\title{
The multi metal-resistant bacterium Cupriavidus metallidurans CH34 affects growth and metal mobilization in Arabidopsis thaliana plants exposed to copper
}

\author{
Claudia Clavero-León ${ }^{1,2}$, Daniela Ruiz ${ }^{1,2}$, Javier Cillero ${ }^{1,2}$, Julieta Orlando ${ }^{3}$, Bernardo González ${ }^{\text {Corresp. } 1,2}$ \\ ${ }^{1}$ Laboratorio de Bioingeniería. Facultad de Ingeniería y Ciencias, Universidad Adolfo Ibáñez, Santiago, Chile \\ 2 (CAPES), Center of Applied Ecology and Sustainability, Santiago, Chile \\ 3 Laboratorio de Ecología Microbiana. Departamento de Ciencias Ecológicas. Facultad de Ciencias, Universidad de Chile, Santiago, Chile \\ Corresponding Author: Bernardo González \\ Email address: bernardo.gonzalez@uai.cl
}

Copper $(\mathrm{Cu})$ is important for plant growth, but high concentrations can lead to detrimental effects such as primary root length inhibition, vegetative tissue chlorosis, and even plant death. The interaction between plant-soil microbiota and roots can potentially affect metal mobility and availability, and, therefore, overall plant metal concentration. Cupriavidus metallidurans $\mathrm{CH} 34$ is a multi metal-resistant bacterial model that alters metal mobility and bioavailability through ion pumping, metal complexation, and reduction processes. The interactions between strain $\mathrm{CH} 34$ and plants may affect the growth, metal uptake, and translocation of Arabidopsis thaliana plants that are exposed to or not exposed to $\mathrm{Cu}$. In this study, we looked also at the specific gene expression changes in C. metallidurans when co-cultured with Cu-exposed $A$. thaliana. We found that $A$. thaliana's rosette area, primary and secondary root growth, and dry weight were affected by strain $\mathrm{CH} 34$, and that beneficial or detrimental effects depended on Cu concentration. An increase in some plant growth parameters was observed at copper concentrations lower than $50 \mu \mathrm{M}$ and significant detrimental effects were found at concentrations higher than $50 \mu \mathrm{M} \mathrm{Cu}$. We also observed up to a $90 \%$ increase and $60 \%$ decrease in metal accumulation and mobilization in inoculated $A$. thaliana. In turn, copper-stressed $A$. thaliana altered $C$. metallidurans colonization, and cop genes that encoded copper resistance in strain $\mathrm{CH} 34$ were induced by the combination of $A$. thaliana and $\mathrm{Cu}$. These results reveal the complexity of the plantbacteria-metal triad and will contribute to our understanding of their applications in plant growth promotion, protection, and phytoremediation strategies. 
1 The multi metal-resistant bacterium Cupriavidus metallidurans $\mathbf{C H 3 4}$ affects growth and

2 metal mobilization in Arabidopsis thaliana plants exposed to copper

3

4 Claudia Clavero-León ${ }^{1,2}$, Daniela Ruiz ${ }^{1,2}$, Javier Cillero ${ }^{1,2}$, Julieta Orlando ${ }^{3}$, and Bernardo

5 González ${ }^{1,2 *}$

6

7 [Laboratorio de Bioingeniería, Facultad de Ingeniería y Ciencias, Universidad Adolfo Ibáñez,

8 Santiago, Chile

$9{ }^{2}$ Center of Applied Ecology and Sustainability (CAPES), Santiago, Chile

10 32Laboratorio de Ecología Microbiana, Departamento de Ciencias Ecológicas, Facultad de Ciencias,

11 Universidad de Chile, Nuñoa, Santiago, Chile

12

13 Running headline: C. metallidurans and $\mathrm{Cu}$ exposed A. thaliana

15 Corresponding author. Bernardo González. Phone: 56-2-23311619. Fax: 56-2-23311906. E-mail:

16 bernardo.gonzalez@uai.cl 


\section{Abstract}

18 Copper $(\mathrm{Cu})$ is important for plant growth, but high concentrations can lead to detrimental

19 effects such as primary root length inhibition, vegetative tissue chlorosis, and even plant death.

20 The interaction between plant-soil microbiota and roots can potentially affect metal mobility and

21 availability, and, therefore, overall plant metal concentration. Cupriavidus metallidurans $\mathrm{CH} 34$

22 is a multi metal-resistant bacterial model that alters metal mobility and bioavailability through

23 ion pumping, metal complexation, and reduction processes. The interactions between strain

$24 \mathrm{CH} 34$ and plants may affect the growth, metal uptake, and translocation of Arabidopsis thaliana

25 plants that are exposed to or not exposed to $\mathrm{Cu}$. In this study, we looked also at the specific gene

26 expression changes in C. metallidurans when co-cultured with $\mathrm{Cu}$-exposed A. thaliana. We

27 found that $A$. thaliana's rosette area, primary and secondary root growth, and dry weight were

28 affected by strain $\mathrm{CH} 34$, and that beneficial or detrimental effects depended on Cu concentration.

29 An increase in some plant growth parameters was observed at copper concentrations lower than

$3050 \mu \mathrm{M}$ and significant detrimental effects were found at concentrations higher than $50 \mu \mathrm{M} \mathrm{Cu}$.

31 We also observed up to a $90 \%$ increase and $60 \%$ decrease in metal accumulation and

32 mobilization in inoculated $A$. thaliana. In turn, copper-stressed $A$. thaliana altered $C$.

33 metallidurans colonization, and cop genes that encoded copper resistance in strain $\mathrm{CH} 34$ were

34 induced by the combination of $A$. thaliana and $\mathrm{Cu}$. These results reveal the complexity of the

35 plant-bacteria-metal triad and will contribute to our understanding of their applications in plant

36 growth promotion, protection, and phytoremediation strategies. 


\section{Introduction}

Copper $(\mathrm{Cu})$, like many other elements, is an essential trace nutrient required for normal plant growth and development (Silver, 1998; Andresen, Peiter, \& Küpper, 2018; Shabbir et al., 2020; Kumar et al., 2021). Required Cu levels in plants range between 5 and $30 \mathrm{mg} \mathrm{kg}^{-1}$, whereas $\mathrm{Cu}$ levels in agricultural soils normally range between 10 and $60 \mathrm{mg} \mathrm{kg}^{-1}$ (Ballabio et al., 2018). Unnatural soil copper sources include manure, sewage sludge, and mineral fertilizers and pesticides (Oorts, 2013), and copper accumulation and leaching are strongly dependent on soil type and conditions (Shabbir et al., 2020). High copper levels negatively affect plants and microorganisms thriving in soil environments (Rajput et al., 2020; Shabbir et al., 2020), leading to the development and expression of detoxification and tolerance processes (Giachino \& Waldron, 2020; Kumar et al., 2021).

Because of its redox potential, $\mathrm{Cu}$ has the ability to cycle between oxidized $\mathrm{Cu}^{2+}$ and reduced $\mathrm{Cu}^{+}$, thus mediating electron transfer reactions as a cofactor in the active centers of several key enzymes. $\mathrm{Cu}^{+}$reduction places $\mathrm{Cu}$ in crucial roles in environmental and physiological processes such as photosynthesis, respiration, reactive oxygen species detoxification, ethylene perception, and cell wall remodeling and lignification (Maksymiec, 1998; Burkhead et al., 2009; Schmidt et al., 2020). These processes have been widely studied in the plant model Arabidopsis thaliana (Lequeux et al., 2010; De Smets et al., 2015; Niu et al., 2019). Cu deficiency and excess cause imbalances in normal plant development and function (Patsikka et al., 2002; DemirevskaKepova et al., 2004). The most common symptoms of $\mathrm{Cu}$ toxicity in plants are primary root length inhibition, vegetative tissue chlorosis, and the imbalanced capture of other relevant trace elements such as Fe, Mn, and Zn (Lequeux et al., 2010; Andrés-Colás et al., 2013). 
In order to fully understand the homeostasis of $\mathrm{Cu}$ and other transition metals in plants,

61 the role of plant-associated microorganisms must be considered (González-Guerrero et al., 2016;

62 Wasai \& Minamisawa, 2018). Soil microorganisms affect trace metal speciation, mobility, and

63 availability in the soil matrix. Processes such as chemical transformation, chelation, and

64 protonation increase the mobilization of trace elements, while precipitation and sorption decrease

65 trace element availability (Gadd, 2004; Mohamad et al., 2012; Rajkumar et al., 2012; Sessitsch

66 et al., 2013; Muehe et al., 2015). However, the role of metal-tolerant soil microorganisms in

67 plant growth is still poorly understood, and additional studies using model microorganisms are

68 clearly needed.

One suitable microorganism is Cupriavidus metallidurans strain $\mathrm{CH} 34$, a well known

70 multi metal-resistant bacterial model that harbors at least 24 metal resistance gene clusters

71 distributed acros four replicons: one chromosome (CHR1), one chromid (CHR2), and two

72 megaplasmids (pMOL28 and pMOL30) (Janssen et al., 2010). This bacterium belongs to the

73 Burkholderiaceae family, which is comprised of members that are capable of inhabiting diverse

74 niches accross sludges, sediments, soils, rhizospheres, and plant roots (Pérez-Pantoja et al.,

75 2012). Strain $\mathrm{CH} 34$ can withstand the millimolar range concentrations of heavy metal ions such

76 as $\mathrm{Cu}^{+}, \mathrm{Cu}^{2+}, \mathrm{Ni}^{2+}, \mathrm{Zn}^{2+}$, and $\mathrm{Co}^{2+}$, all of which are important for plant nutrition (Mergeay et al.,

77 2008; Kirsten et al., 2011). Metal tolerance is mainly achieved by ion efflux, but also by metal

78 complexation and reduction (Mergeay et al., 2003). The role of this strain as a potential plant

79 growth promoting rhizobacterium (PGPR) deserves further study.

80 In this study, we describe, for the first time, the effects of this multi metal-resistant strain

81 on plant growth parameters, and the uptake and mobilization of metals (including several trace

82 metal plant nutrients) in $A$. thaliana individuals that are exposed and not exposed to $\mathrm{Cu}$. We 
83 additionally explored strain $\mathrm{CH} 34$ 's colonization of $A$. thaliana's rhizosphere under these

84 conditions and the transcriptional responses of a few specific genes of $C$. metallidurans $\mathrm{CH} 34$ in

85 an A. thaliana-bacterium co-cultivation system.

\section{Materials and Methods}

\section{Bacterial strains, growth conditions, and $A$. thaliana inoculation}

C. metallidurans $\mathrm{CH} 34$ was obtained from the Deutsche Sammlung von

Mikroorganismen und Zellkulturen GmbH (Braunschweig, Germany). It was routinely grown in

91 Dorn minimal saline medium (Dorn et al., 1974) containing $10 \mathrm{mM}$ gluconate as a sole carbon and energy source in an orbital shaker $(150 \mathrm{rpm})$ at $30^{\circ} \mathrm{C}$. We collected suspensions of cells that were fully grown to the mid-exponential phase $\left(\mathrm{OD}_{600 \mathrm{~nm}}=0.6\right)$, adjusted them to approximately

$9410^{8}$ colony-forming units per milliliter $(\mathrm{CFU} \mathrm{mL}-1)$, and diluted them in agar medium just prior to solidification in order to obtain $10^{4} \mathrm{CFU} \mathrm{mL}-1$ for $A$. thaliana inoculation of a gnotobiotic system. CFU were calculated based on colony counts from serial $1 \mathrm{~mL}$ dilutions (usually $10^{-2}$ to $10^{-8}$ ) of $100-\mu 1$ aliquots plated on three R2A agar plate replicates. Ultimately, the CFU values corresponded to the average of colony counts $\mathrm{x}$ corresponding dilution $\mathrm{x} 10(100 \mathrm{aliquot} / 1000 \mathrm{uL}$ dilution volume). To assess the effect of heat-inactivated bacteria, we heated an inoculum suspension at $95^{\circ} \mathrm{C}$ for 20 min prior to the final dilution in agar medium. This temperature was

101 high enough to kill all bacterial cells without destroying them (Poupin et al., 2013). Bacterial cell 102 viability was routinely confirmed using R2A medium agar plate counting. 
106 (Ohio State University, Columbus, OH, USA). The seeds were surface sterilized with 95\%

107 ethanol commercial laundry bleach (50\%), rinsed three times with sterile water, and kept at $4^{\circ} \mathrm{C}$

108 for 4 days to synchronize germination. Sterility was demonstrated in R2A or Luria Bertani media

109 agar plates inoculated with aliquots of the solution used to wash seeds. Square Petri dishes were

110 prepared with half-strength Murashige-Skoog medium (MS1/2) (Murashige \& Skoog, 1962), 0.8\%

111 agar, and 1.5\% sucrose (a carbon source for the plant, not for strain $\mathrm{CH} 34$ ); were either inoculated

112 or not inoculated with strain $\mathrm{CH} 34$; and were supplemented with $0,25,50,60$, and $70 \mu \mathrm{M}$

$113 \mathrm{CuSO}_{4} \times 5 \mathrm{H}_{2} \mathrm{O}$. The Petri dishes were then vertically placed in a growth chamber and incubated at

$11420-22^{\circ} \mathrm{C}$ under a 16:8h (long day) light:dark cycle. It should be noted that the copper

115 concentration in the MS medium was $0.1 \mu \mathrm{M}$. We measured the $A$. thaliana growth parameters 21

116 days after sowing (DAS) to ensure that the parameters and bacterial colonization tests were

117 accurate (Poupin et al., 2013; Zúñiga et al., 2017). The rosette areas were calculated using

118 Adobe ${ }^{\circledR}$ Photoshop ${ }^{\circledR}$ Cs3 software (Adobe ${ }^{\circledR}$ Systems Incorporated, San Jose, CA, USA). We

119 measured the primary root growth using a ruler and counted the secondary roots. Fresh weight

120 (FW) and dry weight (DW) were determined using a Shimadzu analytical balance (Shimadzu

121 Corporation, Kyoto, Japan).

122

123 Rhizosphere and A. thaliana colonization

To quantify bacterial colonization, we removed $A$. thaliana individuals at 21 DAS from

125 inoculated agar that was either supplemented or not supplemented with $50 \mu \mathrm{M} \mathrm{CuSO}_{4} \times 5 \mathrm{H}_{2} \mathrm{O}$,

126 and used vortex agitation to wash roots in a $10 \mathrm{mM} \mathrm{MgSO}_{4} \times \mathrm{H}_{2} \mathrm{O}$ solution in order to release

127 their attached bacteria cells. The copper concentration was chosen based on its relation with 
128 positive or negative effects on A. thaliana. The extracted liquid was serially diluted with the

129 same solution before plating on R2A agar plates, and the $\mathrm{CFU} \mathrm{mg}{ }^{-1} \mathrm{FW}$ values were determined

130 after $24 \mathrm{~h}$ of incubation at $30^{\circ} \mathrm{C}$. To quantify rhizosphere colonization, we used vortex agitation

131 to wash the roots in a $10 \mathrm{mM} \mathrm{MgSO}{ }_{4} \times \mathrm{H}_{2} \mathrm{O}$ solution in order to release the samples of agar

$132\left(\mathrm{MS}^{1 / 2} 2\right.$ medium) that were in close contact with the roots (rhizosphere agar at a distance of less

133 than $1 \mathrm{~cm}$ ) and attached bacteria cells. We used A. thaliana plants that were grown without strain

$134 \mathrm{CH} 34$ inoculation to check the sterility of the conditions. Sterility was proved after inoculation of

135 aliquots from the solution used to wash samples of the agar material attached to roots, in rich

136 media agar plates as indicated above. Agar plates without A. thaliana, and either supplemented

137 with or without $50 \mu \mathrm{M} \mathrm{CuSO}_{4} \times 5 \mathrm{H}_{2} \mathrm{O}$, were used to determine $A$. thaliana's influence on

138 bacterial growth. Agar material samples were also washed with a $10 \mathrm{mM} \mathrm{MgSO}_{4} \times 7 \mathrm{H}_{2} \mathrm{O}$ solution.

140 Metal quantification in $A$. thaliana tissues

141 For total metal quantification, we separated the rosettes and roots of A. thaliana

142 individuals $21 \mathrm{DAS}$, cultivated in the presence of $50 \mu \mathrm{M} \mathrm{CuSO}_{4} \times 5 \mathrm{H}_{2} \mathrm{O}$, and either inoculated or

143 not inoculated with strain $\mathrm{CH} 34$, and rinsed them six times with ultra pure water. After drying

144 for $24 \mathrm{~h}$ at $50^{\circ} \mathrm{C}$, the rosettes and roots material was separated into three $8 \mathrm{mg} \mathrm{DW}$ groups and

145 digested using a $\mathrm{HNO}_{3}: \mathrm{H}_{2} \mathrm{O}_{2}=2: 1$ mixture in a high-performance microwave (Milestone, Ethos

146 One, Brondby, Denmark). Metal analysis was performed using an ICP-MS Thermo Scientific X

147 Series 2 spectrometer (ThermoFisher Scientific, Waltham, MA, USA). We calculated the

148 translocation factor (TF) for each metal as the ratio between the rosette metal g-1 $\mu$ g and the root

149 metal $\mathrm{g}^{-1} \mu \mathrm{g}$, for each condition. Metal contents were determined by multiplying each sample

150 concentration by the DW. 


\section{Bacterial gene expression tests in A. thaliana-bacterium co-cultivation assays}

To evaluate $C$. metallidurans $\mathrm{CH} 34$ gene expression in the presence of $A$. thaliana, we

154 performed co-cultivation assays in hydroponic cultures. In order to allow adequate A. thaliana

155 growth, 60 previously sterilized seeds were sown in the sterile conditions described above: MS

$156(100 \%)$ medium supplemented with $3 \%$ sucrose, and 0 or $25 \mu \mathrm{M} \mathrm{CuSO}_{4} \times 5 \mathrm{H}_{2} \mathrm{O}$. This $\mathrm{Cu}$

157 concentration was chosen again because no detrimental effects were observed in the other $A$.

158 thaliana individuals. A. thaliana growth was carried out under the same conditions as the in vitro

159 cultures. At 21 DAS, the hydroponic cultures were inoculated with $1 \times 10^{4}$ cells $/ \mathrm{mL}$ of strain

$160 \mathrm{CH} 34$. We interrupted the $A$. thaliana-bacterium interaction using quenching buffer (methanol

$16160 \%, 62.5 \mathrm{mM}$ HEPES, and distilled water) after 30, 60, and $180 \mathrm{~min}$ of inoculation, and stored

162 the biological material at $-80^{\circ} \mathrm{C}$. These time periods were chosen because $A$. thaliana already

163 influences bacterial gene expression (Zúñiga et al., 2013; 2017). We used the same hydroponic

164 systems that were inoculated with strain $\mathrm{CH} 34$ without $A$. thaliana, along with a growth medium

165 containing gluconate supplemented with 0 or $25 \mu \mathrm{M} \mathrm{CuSO}_{4} \times 5 \mathrm{H}_{2} \mathrm{O}$, as the control to verify the

166 effects on the induction and repression of bacterial genes in the absence of $A$. thaliana or $\mathrm{Cu}$.

\section{Quantitative real time polymerase chain reaction (qRT-PCR) analysis}

169 To extract RNA, we processed $4 \mathrm{ml}$ of each co-cultivation assay using the geneJET RNA

170 purification kit (ThermoFisher Scientific, Waltham, MA, USA). The RNA was quantified using

171 an $\mathrm{EON}^{\mathrm{TM}}$ microplate reader (BioTek ${ }^{\circledR}$, Winoosky, VT, USA) and treated with the TURBO

172 DNase kit (Ambion, Austin, TX, USA) to remove DNA contamination. cDNA synthesis was 
173 performed using the ImProm-II ${ }^{\mathrm{TM}}$ Reverse Transcription System (Promega Corporation,

174 Madison, WI, USA) with $1 \mu \mathrm{g}$ of RNA in $20 \mu \mathrm{L}$ reactions. RT-PCR was performed using the

175 Brilliant SYBR ${ }^{\circledR}$ Green QPCR Master Reagent kit (Agilent Technologies, Santa Clara, CA,

176 USA) and the Eco ${ }^{\mathrm{TM}}$ Real-Time PCR detection system (Illumina ${ }^{\circledR}$, San Diego, CA, USA). The

177 PCR mixture $(10 \mu \mathrm{L})$ contained $2 \mu \mathrm{L}$ of template cDNA (diluted $1: 10)$ and $100 \mathrm{nM}$ of each

178 primer. Amplification was performed under the following conditions: $95^{\circ} \mathrm{C}$ for $10 \mathrm{~min}$; followed

179 by 40 cycles of $94^{\circ} \mathrm{C}$ for $30 \mathrm{~s}, 60^{\circ} \mathrm{C}$ for $30 \mathrm{~s}$, and $72^{\circ} \mathrm{C}$ for $30 \mathrm{~s}$; followed by a melting cycle

180 from $55^{\circ}$ to $95^{\circ} \mathrm{C}$. Relative gene expression calculation was conducted as described in the

181 software manufacturer's instructions (Illumina ${ }^{\circledR}$, San Diego, CA, USA). We calculated an

182 accurate ratio between the expression of the gene of interest (GOI) and the housekeeping (HK)

183 gene (16S rRNA) according to $2-(\Delta \mathrm{CtGOI}-\mathrm{HK})$. Firstly, we normalized using a ratio between

184 the GOI and the $16 \mathrm{~S}$ gene (as HK). Then, we used the time 0 treatment (before any treatment

185 with MS or plant exudates) as the calibrating condition. The previous allows us to compare each

186 treatment data with the others. It should be mentioned that the use of $16 \mathrm{~S}$ rRNA is only for

187 preliminary and explorative purposes and subsequent studies should include more appropriate

188 housekeeping genes. Gene expression levels were normalized to the average expression level

189 values in the control treatment. We also used reported primer pairs for $\operatorname{cop} K, \operatorname{cop} C, \operatorname{cop} C 2$, and

$190 \operatorname{cop} F$ gene sequences (Table 1), which were involved in the copper resistance of strain CH34

191 (Monchy et al., 2006). Primer pairs for aleO, iucA, aleB, piuA, phaCl, catA, pcaG, bvgA, and

$192 p h c A$ genes (Table 1), involved in potential bacterial-plant interactions, were designed using

193 Primer 3 version 0.4.0 (http://primer3.ut.ee). All PCR determinations were performed using at

194 least three biological replicates and two technical replicates per treatment. 


\section{Statistical analysis}

The statistical analyses of $A$. thaliana growth parameters were performed using the two-way analysis of variance (ANOVA). Tukey's honest significant difference $(\mathrm{P}<0.05)$ test was used to make comparisons across different treatments.

\section{Results}

\section{C. metallidurans $\mathrm{CH34}$ effects on A. thaliana growth with varied $\mathrm{Cu}$ concentrations}

We carried out in vitro $A$. thaliana-bacterium co-cultivation assays using a $\mathrm{MS}^{1} / 2$

204 medium supplemented with 0 to $70 \mu \mathrm{M} \mathrm{Cu}^{2+}$ over a 21-day period in order to test the effects of 205 strain $\mathrm{CH} 34$ on growth. These $\mathrm{Cu}^{2+}$ concentrations, particularly higher ones, caused mild to high stress in plants, reduced biomass, and increased chlorosis (Lequeux et al., 2010; Andrés-Colás et al., 2013). The presence of strain CH34 significantly altered $A$. thaliana's rosette area, primary and secondary root growth, and FW and DW at all copper concentrations when compared with the non-inoculated group (Fig. $1 \mathrm{~A}$ and $\mathrm{B})$. When $\mathrm{Cu}$ concentrations were low to intermediate $(0$

$210-50 \mu \mathrm{M})$, strain $\mathrm{CH} 34$ had a positive effect on $A$. thaliana, increasing its primary root length by

$21119.4 \%, 53.7 \%$, and $19.0 \%$ in treatments with 0,25 , and $50 \mu \mathrm{M} \mathrm{Cu}^{2+}$, respectively. The number

212 of secondary roots also increased by $26.4 \%$ at $25 \mu \mathrm{M} \mathrm{Cu}^{2+}$, and the rosette area increased by

$21310.3 \%$ and $21.0 \%$ at 0 and $25 \mu \mathrm{M} \mathrm{Cu}^{2+}$, respectively. These changes in plant growth parameters

214 appear to be modest, at first instance, but truly reflect effects of the presence of a single

215 bacterium population on the plant.

216 However, at intermediate to high $\mathrm{Cu}^{2+}$ concentrations $(50-70 \mu \mathrm{M})$, strain $\mathrm{CH} 34$ had

217 detrimental effects on primary root length, decreasing it by 20.0 and $86 \%$ in treatments with 60 218 and $70 \mu \mathrm{M}$, respectively, when compared with the non-inoculated control group. Rosette areas 
219 were reduced by $53.0,60.0$, and $75.3 \%$ at 50,60 , and $70 \mu \mathrm{M}$ of $\mathrm{Cu}^{2+}$, respectively. FW and DW

220 decreased in all inoculated treatments, except at $25 \mu \mathrm{M} \mathrm{Cu}^{2+}$ concentration, when compared to

221 the non-inoculated condition (Fig. 1B). The decrease in FW and DW correlated with decreases

222 in other A. thaliana growth parameters (Fig 1B), except for root growth at 0 days, which might

223 be explained by the initial reallocation of A. thaliana root resources upon bacterial inoculation.

224 Both beneficial and detrimental effects were clearly caused by live $\mathrm{CH} 34$ cells, as the tests

225 performed with heat-killed cells showed identical results as those of the non-inoculated control

226 group (Supplementary Material, Fig. S1).

227

228

229

In control and $\mathrm{Cu}$-exposed rosettes and roots, $C$. metallidurans $\mathrm{CH} 34$ modifies the accumulation and translocation of metals present in the $A$. thaliana growth medium

$\mathrm{Cu}$ may affect $A$. thaliana growth parameters (Fig. 1) via metal mobilization mediated by

231

C. metallidurans (Nies, 2016). Therefore, we quantified the rosette and root tissue distribution of

232

the main seven metals that composed the MS medium. Although not accurate, for simplicity we

233

refer to boron as a metal. The metals and their concentrations were optimized for plant growth in

234 the MS medium (Murashige \& Skoog, 1962). However, when present in higher levels, these

235 seven metals are toxic plant growth inhibitors (Andresen et al., 2018). In inoculated A. thaliana,

236 the absence of $\mathrm{Cu}$ caused a significant increase in B (29 and 32\%), Co (68 and 67\%), $\mathrm{Cu}$ (11 and

237 18\%), Fe (42 and 91\%), and Mn (11 and 46\%) levels in rosettes and roots, respectively.

238 However, Mo levels decreased (61\%) and $\mathrm{Zn}$ levels increased (38\%) in roots (absolute and

239 relative values in Tables 2 and 3, respectively). In inoculated A. thaliana, the presence of $\mathrm{Cu}^{2+}$

240 significantly increased Co (40 and 73\%), Cu (55 and 38\%), Mn (33 and 10\%), Mo (60 and 64\%),

241 and $\mathrm{Zn}(21$ and $71 \%)$ levels in rosettes and roots, respectively. B (30\%) and Fe (9\%) increased in 
242 rosettes only, Fe (31\%) decreased in roots, and B levels in roots were not affected (Tables 2 and

243 3). In non-inoculated $A$. thaliana, $50 \mu \mathrm{M} \mathrm{Cu}^{2+}$ increased B (109 and 380\%), Co (50 and 20\%),

$244 \mathrm{Cu}$ (315 and 493\%), Fe (277 and 315\%), Mn (33 and 59\%), and Zn (54 and 30\%), and decreased

245 Mo (27\% and 70\%) levels in rosettes and roots, respectively (Tables 2 and 3). To evaluate the

246 metal mobility of $A$. thaliana roots and rosettes, TF values were determined for each metal

247 (Table 4). In non-inoculated $A$. thaliana, we found that $\mathrm{Cu}$ clearly altered metal mobility because

248 in the absence of $\mathrm{Cu}^{2+}$, the TFs for $\mathrm{Co}(1.5$-fold $)$ and Mo (2.3-fold) increased, and the TFs for $\mathrm{Cu}$

249 (0.7-fold), Mn (0.8-fold), and B (0.4-fold) decreased. Strain CH34 innoculation in the absence of

$250 \mathrm{Cu}$ changed the TFs of all elements except for B and $\mathrm{Co}$, but in the presence of $\mathrm{Cu}$, the strain

251 modified all TFs except for Mo (Table 4). In the absence of strain $\mathrm{CH} 34, \mathrm{Cu}^{2+}$ drastically

252 changed the metal accumulation in $A$. thaliana roots and rosettes, with much higher $\mathrm{B}, \mathrm{Cu}$, and

253 Fe accumulation; mild $\mathrm{Co}, \mathrm{Mn}$, and $\mathrm{Zn}$ accumulation; and negative (less accumulation in the

254 presence of $50 \mu \mathrm{M} \mathrm{Cu}^{2+}$ ) Mo accumulation (Table 3).

255

256 Copper-stressed $A$. thaliana changed $C$. metallidurans CH34 colonization and the

257 transcriptional levels of some genes

258

To further explore Cu's effects on the A. thaliana-C. metallidurans interaction, we

259

conducted rhizospheric and colonization tests in the presence of $50 \mu \mathrm{M} \mathrm{Cu}^{2+}$. This concentration

260

was chosen because it provoked intermediate effects on $A$. thaliana growth parameters. $C$.

261 metallidurans effectively colonized $\left(1 \times 10^{8} \mathrm{CFU} \mathrm{mL}-1\right)$ both A. thaliana and its rhizospheric

262 surroundings. Adding copper produced significant changes on the bacterial colonization by both

263 increasing bacteria directly adhered to $A$. thaliana roots by 3.1 times and decreasing

264 colonization in its vicinity by 7.1 times (Table 5). It should be noted that we observed positive 
265 effects on strain $\mathrm{CH} 34$ colonization as a 4-log increase in $\mathrm{CFU}$ with respect to the non-

266 rhizospheric conditions was recorded (Table 5).

267 To further understand the effects of strain $\mathrm{CH} 34$ on $A$. thaliana protection, colonization,

268 and metal translocation, we carried out a transcriptional analysis of a small subset of genes.

269 These experiments were performed in A. thaliana hydroponic cultures in order to fulfill the

270 quality requirements for bacterial RNA extraction. Since $\mathrm{Cu}$ has a greater presence in hydroponic

271 medium than in agar plates (Burkhead et al., 2009), we used a $25 \mu \mathrm{M} \mathrm{Cu}^{2+}$ concentration to

272 emulate the $50 \mu \mathrm{M} \mathrm{Cu}^{2+}$ used in agar plate $A$. thaliana tests in order to provoke similar effects.

273 At 21 days, C. metallidurans was inoculated and RNA was extracted after 30, 60, and 180 min

274 from the hydroponic cultures. These bacteria - A. thaliana interaction times were selected based

275 on a previous study that used a similar Burkholderiaceae bacterium (Zúñiga et al., 2017). Three

276 groups of genes were chosen to perform a RT-qPCR analysis: a set of cop genes involved in $\mathrm{Cu}$

277 detoxification, a set of siderophore-related genes, and a set of colonization-related genes

278 (Janssen et al., 2010). Fig. 2 shows the relative expression levels of the genes associated with

279 copper resistance: $\operatorname{cop} K, \operatorname{cop} F, \operatorname{cop} C$, and $\operatorname{cop} C 2$. The first three genes are located in the

280 megaplasmid pMOL30 in a cluster of 21 cop genes and they encode proteins involved in

281 periplasmic ( $\operatorname{cop} K$ and $\operatorname{cop} C$ ) and cytoplasmic ( $\operatorname{cop} F)$ detoxification. $\operatorname{cop} C 2$, located on a smaller

282 cluster of cop genes $\left(\operatorname{copD}_{2} C_{2} B_{2} A_{2} R_{2} S_{2}\right)$, is strongly induced mainly at concentrations lower than

$283100 \mu \mathrm{M} \mathrm{Cu}^{2+}$ (Janssen et al., 2010). copK was clearly expressed 60 min after $A$. thaliana

284 inoculation (Fig. 2), with induction still observable after $180 \mathrm{~min}$ in the presence, but not in the

285 absence, of $\mathrm{Cu}^{2+}$. $\operatorname{cop} C$ only showed a transient significant induction in the presence of $\mathrm{Cu}^{2+}$.

$286 c o p F$ gene expression levels remained essentially unchanged and $\operatorname{cop} C 2$ expression levels

287 noticeably decreased in the presence of $A$. thaliana (Fig. 2). 
A second set of targeted genes were involved in the regulation, production, and sensing of

C. metallidurans $\mathrm{CH} 34$ staphyloferrin B siderophore. A previous study found that $C$.

metallidurans $\mathrm{CH} 34$ affects metal availability by producing a unique phenolate-type siderophore

that has been described to bind $\mathrm{Cd}^{2+}$ (Gilis et al., 1998). The Fur protein (aleO gene) is a

transcriptional regulator involved in Fe metabolism that represses staphyloferrin B synthesis

293

294

295

296

297

298

299

300

301

302

303

304

305

306

307

308

309

310

under optimal Fe conditions, although it has been suggested that the transcriptional activation of other genes is also involved in Fe regulation (Ma, Jacobsen \& Giedroc, 2009). After 30 and 180 min of C. metallidurans $\mathrm{CH} 34$ inoculation, Fur regulator expression was significantly repressed in both $A$. thaliana-only and $A$. thaliana plus $25 \mu \mathrm{M} \mathrm{Cu}^{2+}$-conditions, suggesting that $\mathrm{Fe}$ requirement should not be as severe as in $25 \mu \mathrm{M} \mathrm{Cu}^{2+}$-only conditions (Fig. 3). The iucA gene, one of the three genes responsible for staphyloferrin B synthesis, was only significantly induced in $25 \mu \mathrm{M} \mathrm{Cu}^{2+}$-only conditions (Fig. 3), while the staphyloferrin B receptor aleB gene was induced after 60 and 180 min of inoculation in the presence of $A$. thaliana. The piuA gene encoding a siderophore/iron-complexation receptor was not involved in staphyloferrin B uptake, and was only induced in the $25 \mu \mathrm{M} \mathrm{Cu}^{2+}$-only condition (Fig. 3). Finally, we analyzed the expression changes in phaCl (polyhydroxybutyrate synthesis), catA (catechol), pcaG (protocatechuate catabolism), $b v g A$ (transcriptional activator of virulence and colonization factors), and $p h c A$ (virulence regulator) genes. $p h a C 1$ was the only gene that showed clear induction by $A$. thaliana (peaked at $30 \mathrm{~min}$, Supplementary Material Fig. S2), as the other four tested genes were either not induced, or only poorly induced, by $A$. thaliana. Since the same medium was used across all tests, phaCl gene's changes could not be explained by phosphate changes.

Peer) reviewing PDF | (2020:08:52339:2:0:NEW 4 Apr 2021) 


\section{Discussion}

312 Our results indicate that the C. metallidurans-A. thaliana interaction is characterized by

313 a dual effect on plant growth and metal availability. A dependence on $\mathrm{Cu}^{2+}$ levels, and

314 significant effects on of $A$. thaliana's bacterium colonization and bacterial gene expression. We

315 have previously demonstrated that closely related species such as $C$. pinatubonensis and $P$.

316 phytofirmans have also PGPR abilities (Ledger et al., 2012, Poupin et al., 2013; Zúñiga et al.,

$3172013,2017)$ but not showing this dual effect.

318 C. metallidurans' ability to act as a PGPR (see the increase in root length at low $\mathrm{Cu}^{2+}$

319 levels, Fig. 1), at least in A. thaliana, is not surprising as several members of the Cupriavidus

320 genus and the Burkholderiaceae family are well-known PGPRs or, at least, interact with plants

321 (Gyaneshwar et al., 2011; Bhattacharyya \& Jha, 2012; Poupin et al., 2013, Arroyo-Herrera et

322 al., 2020). Because PGPR traits (Zeffa et al., 2020), including 1-aminocyclopropane-1-

323 carboxylate deaminase, auxin phytohormone production, phosphate solubilization, and nitrogen

324 fixation (Bhattacharyya, Jha, 2012, Aeron et al., 2020), have not yet been reported in $C$.

325 metallidurans, new PGPR traits would be interesting to explore in this bacterium. New PGPR

326 traits could emerge from further in-depth study of the responses that gobernate this

327 interkingdom relationships. Furthermore, the colonization behavior reported here is indicative

328 of the inherent dynamics of the rhizospheric environment (Bais et al., 2006; Chaparro et al.,

329 2014) and highlight the importance to describe and study these traits in environmental

330 intertwined plant-microbre systems.

331 Few studies have addressed the effects that $C$. metallidurans $\mathrm{CH} 34$ exerts in plants and

332 their rhizosphere environments. Because it had no apparent plant growth-promoting or protection

333 effects, strain $\mathrm{CH} 34$ has been employed as a neutral bacterium (Taghavi et al., 2009). In a 
334 bioaugmentation-assisted phytoextraction procedure, strain $\mathrm{CH} 34$ was shown to increase $\mathrm{Cr}$ and

$335 \mathrm{~Pb}$ levels in maize shoots by a factor of 4.4 and 3.2, respectively, but it reduced $\mathrm{Cr}$ and $\mathrm{Pb}$ levels

336 in roots by a factor of 2.9 and 4.8 , respectively, illustrating how metal uptake and mobilization

337 depend on metal species and plant tissue (Braud et al., 2009). Our results suggest a possible

338 linkage between the plant metal uptake and the plant development when C. metallidurans $\mathrm{CH} 34$

339 is present. Microbially mediated plant growth promotion effects through metal level increases in

340 Arabidopsis, have been scarcely explored (Lu et al., 2020).

341 The effects of negative $\mathrm{Cu}$ excess on plant growth have been previously studied

342 (Doncheva, 1998; Burkhead et al., 2009; Kumar et al, 2021), and found that Cu mostly

343 accumulates in root tissues (Alaoui-Sossé et al., 2004; Navari-Izzo et al., 2006; Burkhead et al.,

344 2009). Cu provokes the reorganization of root architecture, leading to primary root growth

345 inhibition and secondary root stimulation (Lequeux et al., 2010), although the latter effect has

346 not been observed in A. thaliana, at least under the growth conditions used in this study. The

347 detrimental effects of high $\mathrm{Cu}$ levels reported here may also be related to the uncontrolled

348 mobilization of other micronutrients (Andresen, Peiter, \& Küpper, 2018; Kumar et al., 2021).

349 It can be hypothesized that the dual effect of $C$. metallidurans on $A$. thaliana growth,

350 either beneficial or detrimental depending on the $\mathrm{Cu}$ concentration, may be explained, although

351 not exclusively, by the metal mobilization stimulated by this bacterium (Tables 3 and 4). This

352 strain possesses transport mechanisms for multiple metallic ions, siderophores, and other metal-

353 chelating molecules (Kirsten et al., 2011; Nies, 2016). At low Cu levels, strain CH34 may

354 promote $A$. thaliana growth, increase micronutrient levels, and enhance uptake by roots and

355 further mobilization to upper tissues. At high $\mathrm{Cu}^{2+}$ concentrations, such enhanced uptake and

356 mobilization processes may cause micronutrient tissue accumulation at sub-toxic or toxic 
357 levels, impairing $A$. thaliana growth. It has been previously reported that $\mathrm{Cu}$ can alter the

358 accumulation and translocation of transition metals (Karimi et al., 2012; Andrés-Colás et al.,

359 2013), causing a reduction of $\mathrm{Mn}$ and $\mathrm{Fe}$ and an augmentation of $\mathrm{Zn}$ total content in roots.

360 Under the conditions tested here, Cu's effects were especially significant for B and $\mathrm{Fe}$

361 accumulation, as well as $\mathrm{Cu}$ (Puig et al., 2007; Puig \& Peñarrubia, 2009). Mo mobilization is

362 clearly blocked, in a less clear process (Andresen, Peiter, \& Küpfer, 2018).

363 The discrepancies in our results with those of other studies can probably be explained

364 by our testing of micronutrient concentrations that were lower than those used in other studies

365 (Doncheva 1998; Alaoui-Sossé, et al., 2004; Andrés-Colás et al., 2013; Saleem et al., 2020).

366 Additionally, our experimental approach involved the addition of six metals along with $\mathrm{Cu}$,

367 which has not been previously addressed in literature and has implications for the use of $C$.

368 metallidurans in phytoremediation procedures for metal-containing polluted sites (Gadd, 2004;

369 Glick, 2010; Rajkumar et al., 2012), especially those contaminated with metal mixtures. There

370 have been several recent studies on the use of microorganisms to remediate sites polluted with

371 metal combinations (e.g., Cameron, Mata, \& Riquelme, 2018; Choinska-Pulit, Sobolczyk-

372 Bednarek, \& Laba, 2018). Interestingly, co-inoculation approaches have proved successful

373 when protecting alfalfa from $\mathrm{Cu} / \mathrm{Zn}$ mixtures (Jian et al., 2019), cleaning slurries containing

374 heavy metal mixtures plus polycyclic aromatics (Subashchandrabose et al., 2019), or

375 phytoremediating mine tailings from a $\mathrm{Cu}, \mathrm{Fe}, \mathrm{Zn}$, and sulfur extraction operation (Benidire et

$376 a l, 2021)$. Therefore, strain $\mathrm{CH} 34$ may be a good candidate to be used as a microbuial

377 consortium member in co-inoculation schemes to take advantage of the beneficial properties

378 and to prevent potential deleterious effects (Cillero et al., submitted, Supplementary Material). 
$380 \mathrm{Cu}$, microenvironment conditions next to the plant increased the attraction and/or proliferation

381 of this bacterium, which may be explained by changes produced in the composition of $A$.

382 thaliana root exudates, mainly composed of sugars, amino acids, and aromatic compounds

383 (Sasse, Martinoia, \& Northern, 2018; Vives-Peris et al., 2020). Strain CH34, as well as other

384 closer Cupriavidus strains, is not able to grow on common sugars but it is able to proliferate on

385 A. thaliana root exudates (Cillero et al., submitted, Supplementary Material). Cupriavidus strain

386 genomes usually encode a significant group of genes encoding degradation of aromatic

387 compounds that enable these strains to use a wide range of such organic compounds for growth

388 (Lykidis et al., 2010; Pérez-Pantoja et al., 2012), providing ecologically relevant advantages,

389 such as those reported in the closely-related strain C. pinatubonensis JMP134 (Ledger et al.,

390 2012; Pérez-Pantoja et al., 2015). Additionally, Cu-induced stress in plants may also increase

391 root exudation (Huang et al., 2016). Variations in the rhizosphere microenvironment have a

392 mayor role modulating the rhizospheric microbiome, which is capable of recruit or discard some

393 microbial species to dynamicly adjust benefic or detrimental interactions on the system

394 (Zhalnina et al., 2018). C. metallidurans colonization features reported here may reflect system

395 responses to these microenvironmental changes.

396 We wanted to start exploration of effects in strain $\mathrm{CH} 34$ gene expression of the presence

397 /absence of the plant and $\mathrm{Cu}$. The presence of $A$. thaliana and $\mathrm{Cu}$ differentially affected strain

$398 \mathrm{CH} 34$ expression of some genes. For instance, cop genes involved in metal detoxification (copK

399 and $\operatorname{cop} C$ ) were influenced by $A$. thaliana and $\mathrm{Cu}$ to a greater extent than the other cop genes,

400 suggesting that periplasmic detoxification (Monchy et al., 2006) plays a significant role in the $A$.

401 thaliana-bacterium-metal interaction. Genes involved in Fe turnover were also affected by 
402 interaction in the A. thaliana - C. metallidurans - copper triad, as has been previously reported

403 (Puig et al., 2007). Plant-induced phaCl gene expression was also in accordance with $C$.

404 metallidurans' interactions with A. thaliana, as polyhydroxybutyrate production is an advantage

405 reported during early plant colonization (Kadouri, Jurkevitch, \& Okon, 2005; Balsanelli et al.,

406 2016). Additional studies are clearly required as some no significant changes reported here for

407 earlier times might not be found at later stages (7, or 14 days).

408

409 Conclusion

410 This work contributes to our understanding of plant-microbe interactions. At least for the

411 metal multi-resistant C. metallidurans - A. thaliana system, we established that the dual

412 (beneficial or detrimental) effect is dependent on copper levels, the metal root-to-shoots

413 translocation is affected, and the validation of $A$. thaliana bacterial colonization and expression

414 of some bacterial genes. Therefore, the role of metal-tolerant bacteria thriving in the rhizosphere

415 of the plant-bacteria-metal triad deserves special attention, and plant growth promotion,

416 protection, and/or phytoremediation strategies should be explored. Metal $(\mathrm{Cu})$ levels play a key

417 role and are probably the main factor controlling plant-microbe interactions. However, it should

418 be kept in mind that the results reported here were derived under laboratory conditions. Further

419 research is required to validate plant-metal tolerant bacterium-metal contents under field

420 conditions.

421 Acknowledgements

422 We thank Santiago Andrade for its assistance and technical advice on the use of ICP-MS

423 equipment at Pontificia Universidad Católica de Chile. 


\section{References}

425 Aeron, A., Khare, E., Jha, C.K., Meena, V.S., Aziz, S.M.A., Islam, M.T., et al. (2020) Revisiting

426 the plant growth-promoting rhizobacteria: lessons from the past and objectives for the future.

427 Arch Microbiol 201: 665-676. Doi: 10.1007/s00203-019-01779-w

428 Alaoui-Sossé, B., Genet, P., Vinit-Dunand, F., Toussaint, M., Epron, D. and Badot, P. (2004)

429 Effect of copper on growth in cucumber plants (Cucumis sativus) and its relationships with

430 carbohydrate accumulation and changes in ion contents. Plant Sci 166: 1213-1218.

431 https://doi.org/10.1016/j.plantsci.2003.12.032

432 Andrés-Colás, N., Perea-García, A., Mayo de Andrés, S., Garcia-Molina, A., Dorcey, E.,

433 Rodríguez-Navarro, S. et al (2013) Comparison of global responses to mild deficiency and

434 excess copper levels in Arabidopsis seedlings. Metallomics 5: 1234-1246.

435 https://doi.org/10.1039/C3MT00025G

436 Andresen, E., Peiter, Küpfer, H. (2018) Trace metabolism in plants. J Exp Bot 69: 909-954. doi:

437 10.1093/jxb/erx465

438 Arroyo-Herrera, I., Maldonado-Hernández, J., Rojas-Rojas, F.U., Meza-Radilla, G., Larios-

439 Serrato, V., Vásquez-Murrieta, M.S. et al. (2020) Cupriavidus agavae sp. nov., a species isolated

440 from Agave L. rhizosphere in northeast Mexico. Int J Syst Evol Microbiol 70: 4165-4170. Doi:

441 10.199/ijsem.0.004263

442 Bais, H.P., Weir, T.L., Perry, L.G., Gilroy, S., and Vivanco, J.M. (2006). The role of root

443 exudates in rhizosphere interactions with plants and other organisms. Annu Rev Plant Biol

444 57:233-266. https://doi.org/10.1146/annurev.arplant.57.032905.105159 
445 Ballabio, C., Panagos, P., Lugato, E., Huang, J.H., Orgiazzi, A., Jones, A. et al. (2018) Copper

446 distribution in European topsoils: An assessment base don LUCAS soil survey. Sci Tot Environ 447 636: 282-298. https://doi.org/10.1016/j.scitotenv.2018.04.268

448 Balsanelli, E., Tadra-Sfeir, M.Z., Faoro, H., Pankievicz, V., de Baura, V., Pedrosa, F. et al 449 (2016) Molecular adaptations of Herbaspirillum seropedicae during colonization of maize 450 rhizosphere. Environ Microbiol 18: 2343-2356. https://doi.org/10.1111/1462-2920.12887

451 Bhattacharyya, P. and Jha, D. (2012) Plant growth-promoting rhizobacteria (PGPR): emergence 452 in agriculture. World J Microbiol Biotechnol 28: 1327-1350. https://doi.org/10.1007/s11274-011$453 \quad 0979-9$

454 Braud, A., Jézéquel, K., Bazot, S. and Lebeau, T. (2009) Enhanced phytoextraction of an 455 agricultural $\mathrm{Cr}$ - and $\mathrm{Pb}$-contaminated soil by bioaugmentation with siderophore-producing 456 bacteria. Chemosphere 74: 280-286. https://doi.org/10.1016/j.chemosphere.2008.09.013

457 Burkhead, J.L., Reynolds, K.A., Abdel-Ghany, S.E., Cohu, C.M. and Pilon, M. (2009) Copper 458 homeostasis. New Phytol 182: 799-816. https://doi.org/10.1111/j.1469-8137.2009.02846.x

459 Cameron, H., Mata, M.T. and Riquelme, C. (2018) The effect of heavy metal son the viability of 460 Tetraselmis marina AC16-MESO and an evaluation of the potential use of this microalga in 461 bioremediation. PeerJ 6: e5295. doi: 10.7717/peerj.5295.

462 Chaparro, J.M., Badri, D.V., Vivanco, J.M. (2014) Rhizosphere microbiome assemblage is 463 affected by plant development. ISME J 8:790-803.https://doi.org/10.1038/ismej.2013.196

464 Choinska-Pulit, A., Sobolczyk-Benarek, J., Laba, W. (2018). Optimization of copper, lead and 465 cadmium biosorption onto newly isolated bacterium using a Box-Behnken design. Ecotoxicol 466 Environ Saf 149: 275-283. doi: 10.1016/j.ecoenv.2017.12.008 
467 Demirevska-Kepova, K., Simova-Stoilova, L., Stoyanova, Z., Hölzer, R. and Fellerb, U. (2004)

468 Biochemical changes in barley plants after excessive supply of copper and manganese. Environ 469 Exp Bot 3: 253-266. https://doi.org/10.1016/j.envexpbot.2004.02.004

470 De Smet, S., Cuypers, A., Vangronsveld, J.and Remans, T. (2015) Gene networks involved in 471 hormonal control of root develpoment in Arabidopsis thaliana: A framework for studying its 472 disturbance by metal stress. Int J Mol Sci 16: 19195-19224. Doi: 10.3390/ijms160819195

473 Doncheva, S. (1998) Copper-induced alterations in structure and proliferation of maize root 474 meristem cells. J Plant Physiol 153: 482-487. https://doi.org/10.1016/S0176-1617(98)80178-8

475 Dorn, E., Hellwig, M., Reineke, W. and Knackmuss, H.-J. (1974) Isolation and characterization 476 of a 3-chlorobenzoate degrading pseudomonad. Arch Microbiol 99: 61-70.

477 https://doi.org/10.1007/BF00696222

478 Gadd, G. (2004) Microbial influence on metal mobility and application for bioremediation.

479 Geoderma 122: 109-119. https://doi.org/10.1016/j.geoderma.2004.01.002

480 Giachino, A. and Waldron, K.J. (2020) Copper tolerance in bacteria requires the activation of 481 multiple accessory pathways. Mol Microbiol 114: 377-390. doi: 10.1111/mmi.14522

482 Gilis, A., Corbisier, P., Baeyens, W., Taghavi, S., Mergeay, M. and van der Lelie, D. (1998)

483 Effect of the siderophore alcaligin E on the bioavailability of $\mathrm{Cd}$ to Alcaligenes eutrophus $\mathrm{CH} 34$. 484 J Ind Microbiol Biotechnol 20: 61-68. https://doi.org/10.1038/sj.jim.2900478

485 Glick, B. (2010) Using soil bacteria to facilitate phytoremediation. Biotechnol Adv 28: 367-374.

486 https://doi.org/10.1016/j.biotechadv.2010.02.001

487 González-Guerrero, M., Escudero, V., Saéz, Á. and Tejada-Jiménez, M. (2016) Transition metal 488 transport in plants and associated endosymbionts: Arbuscular mycorrhizal fungi and rhizobia.

489 Front Plant Sci 7: 1088. doi: 10.3389/fpls.2016.01088 
490 Gyaneshwar, P., Hirsch, A.M., Moulin, L., Chen, W.M., Elliott, G.N., Bontemps, C. et al (2011)

491 Legume-nodulating betaproteobacteria: diversity, host range, and future prospects. Molec Plant

492 Microbe Interact 24: 1276-1288. https://doi.org/10.1094/MPMI-06-11-0172

493 Huang, G., Guo, G., Yao, S., and Hu, H. (2016) Organic acids, amino acids compositions in the

494 root exudates and $\mathrm{Cu}$ accumulation in castor (Ricinus communis L.) under $\mathrm{Cu}$ stress. Int J

495 Phytoremediation 18: 33-40. Doi: 10.1080/15226514.2105.1058333

496 Janssen, P.J., van Houdt, R., Moors, H., Monsieurs, P., Morin, N., Michaux, A. et al (2010) The

497 complete genome sequence of Cupriavidus metallidurans strain CH34, a master survivalist in

498 harsh and anthropogenic environments. PLoS One 5: e10433.

499 https://doi.org/10.1371/journal.pone.0010433

500 Jian, L., Bai, X., Zhang, H., Song, X., and Li, Z. (2019) Promotion of growth and metal

501 accumulation of alfalfa by coinoculation with Sinorhizobium and Agrobacterium under copper

502 and zinc stress. PeerJ 7: 6875. Doi: 107717/peerj.6875

503 Kadouri, D., Jurkevitch, E. and Okon, Y. (2005) Ecological and agricultural significance of

504 bacterial polyhydroxyalkanoates. Crit Rev Microbiol 31: 55-67.

505 https://doi.org/10.1080/10408410590899228

506 Karimi, P., Khavari-Nejad, R.A., Niknam, V., Ghahremaninejad, F. and Najafi, F. (2012) The

507 effects of excess copper on antioxidative enzymes, lipid peroxidation, proline, chlorophyll, and

508 concentration of Mn, Fe, and $\mathrm{Cu}$ in Astragalus neo-mobayenii. Scientific World J 2012: 615670.

509 https://doi.org/10.1100/2012/615670

510 Kirsten, A., Herzberg, M., Voigt, A., Seravalli, J., Grass, G., Scherer, J. et al (2011) Contributions

511 of five secondary metal uptake systems to metal homeostasis of Cupriavidus metallidurans CH34.

512 J Bacteriol 193: 4652-4663. DOI:10.1128/JB.05293-11 
513 Kumar, V., Pandita, S., Singh Sidhu, G.P., Sharma, A., Khanna, K., Kaur, P. et al. (2021). Copper

514 bioavailability, uptake, toxicity and tolerance to plants: A comprehensive review. Chemosphere

515 262:127810. DOI:10.1016/j.chemosphere.2020.127810.

516 Ledger, T., Zúñiga, A., Kraiser, T., Dasencich, P., Donoso, R., Pérez-Pantoja, D. and González,

517 B. (2012) Aromatic compounds degradation plays a role in colonization of Arabidopsis thaliana

518 and Acacia caven by Cupriavidus pinatubonensis JMP134. Antonie van Leeuwenhoek J Microbiol

519 101: 713-723. https://doi.org/10.1007/s10482-011-9685-8

520 Lequeux, H., Hermans, C., Lutts, S. and Verbruggen, N. (2010) Response to copper excess in

521 Arabidopsis thaliana: Impact on the root system architecture, hormone distribution, lignin

522 accumulation and mineral profile. Plant Physiol Biochem 48: 673-682.

523 https://doi.org/10.1016/j.plaphy.2010.05.005

524 Lu, Q., Weng, Y., You, Y., Xu, Q., Li, H., Li, Y., et al. (2020) Inoculation with abscisic acid

525 (ABA)-catabolizing bacteria can improve phytoextraction of heavy metal in contaminated soil.

526 Environ Pollut 257:113497. doi:10.1016/j.envpol.2019.113497

527 Lykidis, A., Pérez-Pantoja, D., Ledger, T., Mavrommatis, K., Anderson, I., Ivanova, N. et al.

528 (2010) The complete multipartite genome sequence of Cupriavidus necator JMP134, a versatile

529 pollutant degrader. PLoS One 5: e9729. https://doi.org/10.1371/journal.pone.0009729

530 Ma, Z., Jacobsen, F.E. and Giedroc, D.P. (2009) Coordination chemistry of bacterial metal

531 transport and sensing. Chem Rev 109: 4644-4681. https://doi.org/10.1021/cr900077w

532 Maksymiec, W. (1998) Effect of copper on cellular processes in higher plants. Photosynthetica

533 34: 321-342. https://doi.org/10.1023/A:1006818815528

534 Mergeay, M., Monchy, S., Vallaeys, T., Auquier, V., Benotmane, A., Bertin, P. et al. (2003)

535 Ralstonia metallidurans, a bacterium specifically adapted to toxic metals: towards a catalogue of 
536 metal-responsive genes. FEMS Microbiol Rev 27: 385-410. https://doi.org/10.1016/S0168-

$537 \quad 6445(03) 00045-7$

538 Mergeay, M., Monchy, S., Janssen, P., van Houdt, R. and Leys, N. (2008) Megaplasmids in

539 Cupriavidus genus and metal resistance. Microbial Megaplasmids, Berlin Heidelberg, Germany,

540 Springer-Verlag p. 209-238. https://doi.org/10.1007/978-3-540-85467-8_10

541 Mohamad, O.A., Hao, X., Xie, P., Hatab, S., Lin, Y., and Wei, G. (2012). Biosorption of copper

542 (II) from aqueous solution using non-living Mesorhizobium amorphae strain CCNWGS0123.

543 Microbes Environ 27: 234-241. https://doi.org/10.1264/jsme2.ME11331

544 Monchy, S., Benotmane, M.A., Wattiez, R., van Aelst, S., Auquier, V., Borremans, B. et al.

545 (2006) Transcriptomic and proteomic analyses of the pMOL30-encoded copper resistance in

546 Cupriavidus metallidurans strain CH34. Microbiology 152: 1765-1776.

547 https://doi.org/10.1099/mic.0.28593-0

548 Muehe, E.M., Weigold, P., Adaktylou, I.J., Planer-Friedrich, B., Kraemer, U., Kappler, A. and

549 Behrens, S. (2015). Rhizosphere microbial community composition affects cadmium and zinc

550 uptake by the metal-hyperaccumulating plant Arabidopsis halleri. Appl Environ Microbiol 81:

551 2173-2181. DOI:10.1128/AEM.03359-14

552 Murashige, T. and Skoog, F. (1962) A revised medium for rapid growth and bio assays with

553 tobacco tissue cultures. Physiol Plant 15: 473-497. Doi: Not available

554 Navari-Izzo, F., Cestone, B., Cavallini, A., Natali, L., Giordani, T. and Quartacci, M. (2006)

555 Copper excess triggers phospholipase D activity in wheat roots. Phytochemistry 67: 1232-1242.

556 Nies, D.H. (2016) The biological chemistry of the transition metal "transportome" of

557 Cupriavidus metallidurans. Metallomics 5: 481-507.

558 https://doi.org/10.1016/j.phytochem.2006.04.006 
559 Niu, C., Jiang, M., Li, N., Cao, J., Hou, M., Ni, D.A. and Chu, Z. (2019). Integrated

560 bioinformatics analysis of $\mathrm{As}, \mathrm{Au}, \mathrm{Cd}, \mathrm{Pb}$ and $\mathrm{Cu}$ heavy metal responsive marker genes through

561 Arabidopsis thaliana GEO datasets. PeerJ 7:e6495. Doi: 10.7717/peerj.6495

562 Oorts, K. (2013) Copper. In: Alloway B. (eds) Heavy Metals in Soils. Environmental Pollution,

563 vol 22. Springer, Dordrecht. https://doi.org/10.1007/978-94-007-4470-7_13

564 Pätsikkä, E., Kairavuo, M., Sersen, F., Aro, E.M. and Tyystjärvi, E. (2012) Excess copper

565 predisposes photosystem II to photoinhibition in vivo by outcompeting iron and causing decrease

566 in leaf chlorophyll. Plant Physiol 129: 1359-1367. https://doi.org/10.1104/pp.004788

567 Pérez-Pantoja, D., Donoso, R., Agulló, L., Córdova, M., Seeger, M., Pieper, D.H. and González,

568 B. (2012) Genomic analysis of the potential for aromatic compounds biodegradation in

569 Burkholderiales. Environ Microbiol 14: 1091-1117. https://doi.org/10.1111/j.1462-

$570 \quad 2920.2011 .02613 . x$

571 Pérez-Pantoja, D., Leiva-Novoa, P., Donoso, R., Little, C., Godoy, M., Pieper, D.H. and

572 González, B. (2015) Hierarchy of carbon source utilization in soil bacteria: Hegemonic

573 preference for benzoate in complex aromatic compound mixtures degraded by Cupriavidus

574 pinatubonensis strain JMP134. Appl Environ Microbiol 81: 3914-3924.

575 DOI:10.1128/AEM.04207-14

576 Poupin, M.J., Timmermann, T., Vega, A., Zúñiga, A. and González, B. (2013) Effects of the

577 plant growth-promoting bacterium Burkholderia phytofirmans PsJN throughout the life cycle of

578 Arabidopsis thaliana. PLoS One 8: 22. https://doi.org/10.1371/journal.pone.0069435

579 Puig, S., Andrés-Colás, N., García-Molina, A., and Peñarrubia, L. (2007) Copper and iron

580 homeostasis in Arabidopsis: responses to metal deficiencies, interactions and biotechnological

581 applications. Plant Cell Environ 30: 271-290. doi: 10.1111/j.1365-3040.2007.01642.x 
582 Puig, S., and Peñarrubia, L. (2009) Placing metal micronutrients in context: transport and

583 distribution in plants. Curr Opin Plant Biol 12: 299-306. doi: 10.1016/j.pbi.2009.04.008

584 Rajkumar, M., Sandhya, S., Prasad, M.N. and Freitas, H. (2012) Perspectives of plant-associated

585 microbes in heavy metal phytoremediation. Biotechnol Adv 30: 1562-1574.

586 https://doi.org/10.1016/j.biotechadv.2012.04.011

587 Rajput, V., Minkina, T., Ahmed, B., Sushkova, S., Singh, R. Soldatov, M. et al. (2020)

588 Interaction of copper-based nanoparticles to soil, terrestrial, and aquatic systems: Critical review

589 of the state of the science and future perpectives. Rev Environ Contam Toxicol 252: 51-96. Doi:

590 10.1007/398_2019_34

591 Saleem, M.H., Fahad, S., Rehman, M., Saus, S., Jamal, Y., Khan, S. and Liu, L (2020) Morpho-

592 physiological traits, biochemical response and phytoextraction potential of short-term copper

593 stress on kenaf (Hibiscus cannabinus L.) seedlings. PeerJ 8: e8321. doi: 107717/peerj.8321

594 Sasse, J., Martinoia, E., and Northern, T. (2018) Feed your friends: do plant exudates shape the

595 root microbiome? Trends Plant Sci 23: 25-41. doi: 101016/j.tplants.201709.003

596 Schmidt, S.B., Eisenhut, M. and Schneider, A. (2020) Chloroplast transition metal regulation for

597 efficient photosynthesis. Trends Plant Sci 25: 817-828. Doi:10.1016/j.tplants.2020.03.003

598 Sessitsch, A., Kuffner, M., Kidd, P., Vangronsveld, J., Wenzel, W.W., Fallmann, K. and

599 Puschenreiter, M. (2013) The role of plant-associated bacteria in the mobilization and

600 phytoextraction of trace elements in contaminated soils. Soil Biol Biochem 60: 182-194.

601 https://doi.org/10.1016/j.soilbio.2013.01.012

602 Shabbir, Z., Sardar, A., Shabbir, A., Abbas, G., Shamshad, S., Khalid, S. et al. (2020) Copper

603 uptake, essentiality, toxicity, detoxification and risk assessment in soil-plant environment.

604 Chemosphere 259: 127436. Doi: 10.1016/j.chemosphere.2020.1274436 
605 Silver, S. (1998) The bacterial view of the periodic table: specific functions for all elements.

606 Microbes Environ 13: 177-192. https://doi.org/10.1264/jsme2.13.177

607 Subashchandrabose, S.R., Venkateswarlu, K., Venkidusamy, K., Palanisami, T., Naidu, R., and

608 Megharaj, M. (2019) Bioremediation of soil long-term contaminated with PAHs by algal-

609 bacterial synergy of Chlorella sp. MM3 and Rhodococcus wratislaviensis strain 9 in slurry

610 phase. Sci Tot Env 659: 724-731. doi: 10.1016/j.scitotenv.2018.12.453

611 Taghavi, S., Garafola, C., Monchym S., Newman, L., Hoffman, A., Weyens, N. et al (2009)

612 Genome survey and characterization of endophytic bacteria exhibiting a beneficial effect on

613 growth and development of poplar trees. Appl Environ Microbiol 75: 748-757.

614 DOI:10.1128/AEM.02239-08

615 Vives-Peris, V., de Ollas, C., Gómez-Cadenas, A. and Pérez-Clemente, R.M. (2020) Root

616 exudates: from plant to rhizosphere and beyond. Plant Cell Rep 39: 3-17. Doi: 10.1007/s00299-

$617 \quad 019-02447-5$

618 Wasai, S. and Minamisawa, K. (2018). Plant-associated microbes: from rhizobia to plant

619 microbiomes. Microbes Environ 33: 1-3. https://doi.org/10.1264/jsme2.ME3301rh

620 Zhalnina, K., Louie, K.B., Hao, Z., Mansoori, N., Da Rocha, U.N., Shi, S., et al. (2018) Dynamic

621 root exudate chemistry and microbial substrate preferences drive patterns in rhizosphere

622 microbial community assembly. Nat Microbiol 3:470-480. https://doi.org/10.1038/s41564-018-

$623 \quad 0129-3$

624 Zeffa, D.M., Fantin, L.H., Koltun, A., de Oliveira, A.L.M., Nunes, M.P.B.A, Canteri, M.G. and

625 Goncalves, L.S.A. (2020) Effect of plant growth-promoting rhizobacteria on co-inoculation with

626 Bradyrhizobium in soybean crop: a meta-analysis of studies from 1987 to 2018. PeerJ. 8: e7905.

627 Doi: $10.7717 /$ pperj. 7905 
628 Zúñiga, A., Poupin, M.J., Donoso, R., Ledger, T., Guiliani, N., Gutierrez, R. and González, B.

629 (2013) Quorum sensing and índole-3-acetic acid degradation play a role in colonization and plant

630 growth promotion of Arabidopsis thaliana by Burkholderia phytofirmans PsJN. Mol Plant

631 Microbe Interact 26: 546-553. http://dx.doi.org/10.1094/MPMI-10-12-0241-R

632 Zúñiga, A., Donoso, R., Ruiz, D., Ruz, G. and González, B. (2017) Quorum-sensing systems in

633 the plant growth-promoting bacterium Paraburkholderia phytofirmans PsJN exhibit cross-

634 regulation and are involved in biofilm formation. Mol Plant Microbe Interact 30: 557-565.

635 https://doi.org/10.1094/MPMI-01-17-0008-R

636 
637 Table 1: Sequences of primer pairs designed for this work.

638

\begin{tabular}{|l|l|l|l|}
\hline Gene & Locus tag & Forward primer & Reverse primer \\
\hline aleO & Rmet_5746 & GGAAGACGTCTATCGGACCA & CTGTGGCGTAACAGGATGTC \\
\hline iucA & Rmet_1115 & GCATGTCGTGGATTGATCTG & GTGCAAGGGATATGGCTCAG \\
\hline aleB & Rmet_1118 & ACGAAGAAGGACACGGTCAC & GGGAGATGGCTTGTGTTGTT \\
\hline piuA & Rmet_4617 & TCTCGACGATTTCACGAATG & GCGGTCTCGTCATTGATCTT \\
\hline phaC1 & Rmet_1356 & ACCAATACGACGGCAGAGAG & ACTGAAACGGTTGGGACTTG \\
\hline catA & Rmet_4881 & CGCTGGTAAAGCAGTTCCTC & TTGAACAGATCGGTCGTCAG \\
\hline pcaG & Rmet_4014 & GTCGTTCCGCTTCGTTACC & GCATGAACACCGACACCAT \\
\hline bvgA & Rmet_5714 & CCATTGGAGACTCGCTCTTC & GTCACGACCTTGACCTGCTT \\
\hline phcA & Rmet_2977 & GATGCTGGGCCTGAATATGT & AGAAACTCGCCAACCACCT \\
\hline
\end{tabular}

639 
640 Table 2. Metal levels in rosettes and roots of Arabidopsis thaliana 21 days after sowing,

641 inoculated or not with Cupriavidus metallidurans CH34 in the presence or absence of

642 copper.

\begin{tabular}{|c|c|c|c|c|c|c|c|c|}
\hline & \multicolumn{4}{|c|}{ Rosettes } & \multicolumn{4}{|c|}{ Roots } \\
\hline & \multicolumn{2}{|l|}{$\mathrm{MS}^{1 / 2}$} & \multicolumn{2}{|c|}{$\mathrm{MS}^{1} / 2+50 \mu \mathrm{M} \mathrm{Cu}^{2+}$} & \multicolumn{2}{|l|}{$\mathrm{MS}^{1 / 2}$} & \multicolumn{2}{|c|}{$\mathrm{MS}^{1} / 2+50 \mu \mathrm{M} \mathrm{Cu}^{2+}$} \\
\hline & Control & $+\mathrm{CH} 34$ & Control & $+\mathrm{CH} 34$ & Control & $+\mathrm{CH} 34$ & Control & $+\mathrm{CH} 34$ \\
\hline B & $21.0 \pm 1.6^{\mathbf{a}^{* * *}}$ & $27.5 \pm 2.2^{\mathbf{b}}$ & $44.0 \pm 3.4^{\mathbf{c}}$ & $57.3 \pm 5.3^{\mathbf{d}}$ & $14.6 \pm 2.0^{\mathbf{a}}$ & $19.3 \pm 0.9^{\mathbf{b}}$ & $70.1 \pm 23.4^{\mathbf{c}}$ & $59.2 \pm 23.9^{\mathbf{c}}$ \\
\hline Co & $0.2 \pm 0.0^{\mathbf{a}}$ & $0.3 \pm 0.0^{\mathbf{b}}$ & $0.3 \pm 0^{\mathbf{c}}$ & $0.5 \pm 0.0^{\mathbf{d}}$ & $0.5 \pm 0.1^{\mathbf{a}}$ & $0.9 \pm 0.0^{\mathbf{b}}$ & $0.6 \pm 0.1^{\mathbf{a}}$ & $1.0 \pm 0.1^{\mathbf{b}}$ \\
\hline $\mathrm{Cu}$ & $4.5 \pm 0.0^{\mathbf{a}}$ & $4.7 \pm 0.2^{\mathbf{b}}$ & $186.9 \pm 6.1 \mathrm{c}$ & $289.0 \pm 1.4^{\mathbf{d}}$ & $5.2 \pm 0.1^{\mathbf{a}}$ & $6.2 \pm 0.3^{\mathbf{b}}$ & $308.5 \pm 13.8^{\mathbf{c}}$ & $426.2 \pm 20^{\mathbf{d}}$ \\
\hline $\mathrm{Fe}$ & $118.0 \pm 5.4^{\mathbf{a}}$ & $167.9 \pm 9.0^{\mathbf{b}}$ & $445.0 \pm 34.4^{\mathbf{c}}$ & $484.1 \pm 11.5^{\mathbf{d}}$ & $2671.6 \pm 240.8^{\mathbf{a}}$ & $5091.6 \pm 180.0^{\mathbf{b}}$ & $11098.0 \pm 336.9^{\mathbf{c}}$ & $7636.7 \pm 377.7^{d}$ \\
\hline Mn & $196.5 \pm 9.7^{\mathbf{a}}$ & $217.7 \pm 12.4^{\mathbf{b}}$ & $262.6 \pm 15.4^{\mathbf{c}}$ & $350.4 \pm 7.2^{\mathbf{d}}$ & $111.3 \pm 9.0^{\mathbf{a}}$ & $163.0 \pm 4.1^{\mathbf{b}}$ & $177.1 \pm 9.7^{\mathbf{c}}$ & $195.2 \pm 12.2^{\mathbf{d}}$ \\
\hline Mo & $19.5 \pm 1.4^{\mathbf{a}}$ & $18.4 \pm 2.1^{\mathbf{a}}$ & $14.3 \pm 0.4^{\mathbf{b}}$ & $23.0 \pm 1.2^{\mathbf{c}}$ & $66.1 \pm 7.3^{\mathbf{a}}$ & $25.8 \pm 4.7^{\mathbf{b}}$ & $21.3 \pm 4.1^{\mathbf{c}}$ & $35.0 \pm 1.6^{\mathbf{b}}$ \\
\hline $\mathbf{Z n}$ & $191.4 \pm 17^{\mathbf{a}}$ & $191.8 \pm 16.5^{\mathbf{a}}$ & $295.7 \pm 15.1^{\mathbf{b}}$ & $359.2 \pm 1.5^{\mathbf{c}}$ & $940.4 \pm 56.2^{\mathbf{a}}$ & $1299.2 \pm 55.9^{\mathbf{b}}$ & $1222.8 \pm 46.7^{\mathbf{c}}$ & $2091.8 \pm 107.8^{\mathbf{d}}$ \\
\hline
\end{tabular}

643

** All values are expressed as $\mu \mathrm{g}$ metal $\mathrm{g}^{-1}$ of dry weight. MS $1 / 2$ corresponds to half-diluted

644 standard Murashige-Skoog plant growth medium. $\mathrm{MS}^{1 / 2}+50 \mu \mathrm{M} \mathrm{Cu}^{2+}$ " indicates same medium

645 supplemented with $50 \mu \mathrm{M} \mathrm{CuSO}_{4} \times 5 \mathrm{H}_{2} \mathrm{O}$. Each condition had three technical replicates

646 consisting of at least $8 \mathrm{mg}$ of rosette or root material. Different letters represent significant

647 differences between rosette or root levels of each metal (two-way ANOVA, $p<0.05$; Tukey test, $648 \mathrm{p}<0.05)$. 
650 Table 3. Percentage of metal accumulation in rosettes and roots of Arabidopsis thaliana 21 651 days after sowing, inoculated or not with Cupriavidus metallidurans $\mathbf{C H 3 4}$, in the presence 652 or absence of copper.

\begin{tabular}{|c|c|c|c|c|c|c|}
\hline & \multicolumn{2}{|c|}{ Rosettes (CH34/control) } & \multicolumn{2}{|c|}{ Roots (CH34/control) } & \multirow[t]{2}{*}{ Rosettes $(\mathrm{Cu} /$ control $)$} & \multirow[t]{2}{*}{ Roots $(\mathrm{Cu} /$ control $)$} \\
\hline Element & $\mathrm{MS}^{1 / 2}$ & $\begin{array}{c}\mathrm{MS}^{1 / 2}+50 \\
\mu \mathrm{M} \mathrm{Cu}^{2+}\end{array}$ & $\mathrm{MS}^{1} / 2$ & $\begin{array}{c}\mathrm{MS}^{1 / 2}+50 \\
\mu \mathrm{M} \mathrm{Cu}^{2+}\end{array}$ & & \\
\hline B & $+29 \% * *$ & $+30 \%$ & $+32 \%$ & - & $+109 \%$ & $+380 \%$ \\
\hline Co & $+68 \%$ & $+40 \%$ & $+67 \%$ & $+73 \%$ & $+50 \%$ & $+20 \%$ \\
\hline $\mathbf{C u}$ & $+11 \%$ & $+55 \%$ & $+18 \%$ & $+38 \%$ & +315 & $+493 \%$ \\
\hline $\mathbf{F e}$ & $+42 \%$ & $+9 \%$ & $+91 \%$ & $-31 \%$ & $+277 \%$ & $+315 \%$ \\
\hline Mn & $+11 \%$ & $+33 \%$ & $+46 \%$ & $+10 \%$ & $+33 \%$ & $+59 \%$ \\
\hline Mo & - & $+60 \%$ & $-61 \%$ & $+64 \%$ & $-27 \%$ & $-69 \%$ \\
\hline $\mathbf{Z n}$ & - & $+21 \%$ & $+38 \%$ & $+71 \%$ & $+54 \%$ & $+30 \%$ \\
\hline
\end{tabular}

** All values were calculated as percentages of the metal level ( $\mu \mathrm{g}$ of metal $\mathrm{g}^{-1}$ of dry weight) in

654 inoculated versus non-inoculated plants ( $\mathrm{CH} 34 /$ control), and plants in the presence or absence of

655 copper $(\mathrm{Cu} / \mathrm{control})$. -: Not significant changes.

656 
657 Table 4. Translocation factors (TF) for each metal in Arabidopsis thaliana inoculated or not

658 with Cupriavidus metallidurans $\mathrm{CH34}$, in the presence or absence of copper.

\begin{tabular}{|c|c|c|c|c|}
\hline & \multicolumn{2}{|c|}{$\mathbf{M S}^{1 / 2}$} & \multicolumn{2}{|c|}{$\mathrm{MS}^{1} / 2+50 \mu \mathrm{M} \mathrm{Cu} \mathbf{u}^{2+}$} \\
\hline & $\mathbf{T F}_{\text {Control }}$ & $\mathbf{T F}_{\mathrm{CH} 34}$ & $\mathbf{T F}_{\text {Control }}$ & $\mathbf{T F}_{\mathrm{CH} 34}$ \\
\hline $\mathbf{B}$ & $1.6^{\mathrm{a}}$ & $1.3^{\mathrm{a}}$ & $0.7^{\mathbf{b}}$ & $1.1^{b}$ \\
\hline Co & $0.4^{\mathrm{a}}$ & $0.4^{\mathrm{a}}$ & $0.6^{\mathbf{b}}$ & $0.5^{\mathrm{a}}$ \\
\hline Mo & $0.3^{\mathrm{a}}$ & $0.8^{\mathbf{b}}$ & $0.7^{\mathbf{b}}$ & $0.7^{\mathbf{b}}$ \\
\hline $\mathbf{C u}$ & $0.9^{\mathrm{a}}$ & $0.8^{\mathbf{b}}$ & $0.6^{\mathrm{c}}$ & $0.7^{\mathrm{d}}$ \\
\hline Mn & $1.9^{\mathrm{a}}$ & $1.3^{b}$ & $1.5^{\mathrm{c}}$ & $1.8^{\mathrm{d}}$ \\
\hline $\mathbf{F e}$ & $0.04^{\mathrm{a}}$ & $0.03^{b}$ & $0.04^{\mathrm{a}}$ & $0.06^{\mathbf{c}}$ \\
\hline Zn & $0.2^{\mathrm{a}}$ & $0.1^{\mathrm{b}}$ & $0.2^{\mathrm{c}}$ & $0.1^{\mathrm{d}}$ \\
\hline
\end{tabular}

659 TF was calculated as $=\left(\right.$ Metal concentration Rosette $/$ Metal concentration $\left._{\text {Root }}\right) . \mathrm{MS}^{1} / 2$ corresponds to 660 half-diluted standard Murashige-Skoog plant growth medium. $\mathrm{MS}^{1 / 2}+50 \mu \mathrm{M} \mathrm{Cu}^{2+}$ indicates same 661 medium supplemented with $50 \mu \mathrm{M} \mathrm{CuSO}_{4} \times 5 \mathrm{H}_{2} \mathrm{O}$. Each condition had three technical replicates 662 consisting of at least $8 \mathrm{mg}$ of rosette or root material. Different letters represent significant 663 differences between treatments (two-way ANOVA, $\mathrm{p}<0.05$; Tukey test, $\mathrm{p}<0.05$ ). 
665 Table 5. Colony forming units of Cupriavidus metallidurans CH34 by milligram of fresh 666 weight (CFU mg $^{-1}$ FW) of plant, agar surrounding plant (rhizosphere), and non-planted 667 MS $1 / 2$ agar medium (non-rhizosphere).

\begin{tabular}{|c|c|c|c|}
\hline Treatment & 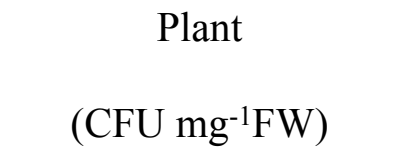 & $\begin{array}{l}\text { Rhizosphere } \\
\text { (CFU mg-1 FW) }\end{array}$ & $\begin{array}{l}\text { Non-rhizosphere } \\
\left(\mathrm{CFU} \mathrm{mg}{ }^{-1} \mathrm{FW}\right)\end{array}$ \\
\hline $\operatorname{MS}(1 / 2)$ & $5.8 \times 10^{8} \pm 4.7 \times 10^{8} \mathbf{a}$ & $1.0 \times 10^{7} \pm 8.5 \times 10^{6} \mathbf{a}$ & $1.7 \times 10^{4} \pm 1.1 \times 10^{4} \mathbf{a}$ \\
\hline $\mathrm{MS}(1 / 2)+50 \mu \mathrm{M} \mathrm{Cu}^{2+}$ & $1.8 \times 10^{9} \pm 7.5 \times 10^{7} \mathbf{a}$ & $1.4 \times 10^{6} \pm 1.2 \times 10^{6} \mathbf{b}$ & $3.6 \times 10^{4} \pm 1.3 \times 10^{4} \mathbf{b}$ \\
\hline
\end{tabular}

C. metallidurans $\mathrm{CH} 34 \mathrm{CFU} \mathrm{mg}^{-1} \mathrm{FW}$ were counted in 21 days after sowing plants, rhizosphere 670 agar and non-rhizosphere $\mathrm{MS}^{1}{ }_{2}$ agar, in 0 and $50 \mu \mathrm{M} \mathrm{CuSO}_{4} \times 5 \mathrm{H}_{2} \mathrm{O}$ treatments. Plants were 671 initially inoculated with $1.0 \times 10^{4} \mathrm{CFU} \mathrm{ml}^{-1}$. The average values of $15-20$ replicates and their 672 respective standard deviations are shown. FW corresponds to that of plant or agar material.

673 Different letters in same column indicate statistically significant differences according to a t-test, $674 \mathrm{p}<0.05$. 


\section{Figure legends}

677 Fig. 1. Effect of Cupriavidus metallidurans CH34 on growth parameters of Arabidopsis

678 thaliana. Rosette area, primary root growth, secondary roots and fresh and dry weights of $A$.

679 thaliana Col-0 grown in in vitro gnotobiotic cultures using half strength Murashige-Skoog (MS)

680 agar medium, inoculated with $1 \times 10^{4}$ colony forming units per milliliter of C. metallidurans

$681 \mathrm{CH} 34$. Forty plants per condition were inoculated or not at day 1 and the half strength MS

682 medium was supplemented with 0 to $70 \mu \mathrm{M} \mathrm{CuSO}_{4} \times 5 \mathrm{H}_{2} \mathrm{O}$. (A) Representative control and strain

$683 \mathrm{CH} 34$ inoculated plants grown in the presence of different $\mathrm{Cu}$ concentrations. (B) Plant growth

684 parameters registered after 21 days of sowing. Bars show mean percentage values, and error bars

685 indicate standard deviations from experiments with 30 plants analyzed for each bacterial

686 condition. Different letters indicate statistically significant differences among treatments at each

687 copper concentration for each measured parameter (Two way ANOVA Tukey's HSD tests; $\mathrm{p}<$ $6880.05)$

689

690 Fig. 2. Relative expression levels of $\mathrm{Cu}$ resistance genes from Cupriavidus metallidurans

691 CH34, in the presence or in the absence of Arabidopsis thaliana or copper. Quantitative Real

692 Time Polymerase Chain Reactions determinations of relative expression levels were normalized

693 respect to the housekeeping gene 16S rRNA. Data correspond to means \pm standard deviations of 694 at least three biological replicates. Different letters indicate significant differences between same 695 time conditions (Two way ANOVA Tukey's HSD tests; $\mathrm{p}<0.05$ ).

696

697 Fig. 3. Relative expression levels of staphyloferrin B siderophore production genes from 698 Cupriavidus metallidurans CH34, in the presence or in the absence of Arabidopsis thaliana 
699 or copper. Quantitative Real Time Polymerase Chain Reactions determinations of relative

700 expression levels were normalized respect to the housekeeping gene 16S rRNA. Data correspond

701 to means \pm standard deviations of at least three biological replicates. The insert shows zoomed

702 Fur (aleO) gene levels. Different letters indicate significant differences between same time

703 conditions (Two way ANOVA Tukey's HSD tests; $\mathrm{p}<0.05$ ).

704 


\section{Table $\mathbf{1}$ (on next page)}

Table 1

Table 1: Sequences of primer pairs designed for this work. 
2 Table 1: Sequences of primer pairs designed for this work.

\begin{tabular}{|l|l|l|l|}
\hline Gene & Locus tag & Forward primer & Reverse primer \\
\hline aleO & Rmet_5746 & GGAAGACGTCTATCGGACCA & CTGTGGCGTAACAGGATGTC \\
\hline iucA & Rmet_1115 & GCATGTCGTGGATTGATCTG & GTGCAAGGGATATGGCTCAG \\
\hline aleB & Rmet_1118 & ACGAAGAAGGACACGGTCAC & GGGAGATGGCTTGTGTTGTT \\
\hline piuA & Rmet_4617 & TCTCGACGATTTCACGAATG & GCGGTCTCGTCATTGATCTT \\
\hline phaC1 & Rmet_1356 & ACCAATACGACGGCAGAGAG & ACTGAAACGGTTGGGACTTG \\
\hline catA & Rmet_4881 & CGCTGGTAAAGCAGTTCCTC & TTGAACAGATCGGTCGTCAG \\
\hline pcaG & Rmet_4014 & GTCGTTCCGCTTCGTTACC & GCATGAACACCGACACCAT \\
\hline bvgA & Rmet_5714 & CCATTGGAGACTCGCTCTTC & GTCACGACCTTGACCTGCTT \\
\hline phcA & Rmet_2977 & GATGCTGGGCCTGAATATGT & AGAAACTCGCCAACCACCT \\
\hline
\end{tabular}




\section{Table 2 (on next page)}

Table 2

Table 2. Metal levels in rosettes and roots of Arabidopsis thaliana 21 days after sowing, inoculated or not with Cupriavidus metallidurans $\mathrm{CH} 34$ in the presence or absence of copper. 
1 Table 2. Metal levels in rosettes and roots of Arabidopsis thaliana 21 days after sowing,

2 inoculated or not with Cupriavidus metallidurans CH34 in the presence or absence of

3 copper.

\begin{tabular}{|c|c|c|c|c|c|c|c|c|}
\hline & \multicolumn{4}{|c|}{ Rosettes } & \multicolumn{4}{|c|}{ Roots } \\
\hline & \multicolumn{2}{|l|}{$\mathrm{MS}^{1 / 2}$} & \multicolumn{2}{|c|}{$\mathrm{MS}^{1 / 2}+50 \mu \mathrm{M} \mathrm{Cu}^{+2}$} & \multicolumn{2}{|l|}{$\mathrm{MS}^{1 / 2}$} & \multicolumn{2}{|c|}{$\mathrm{MS}^{1 / 2}+50 \mu \mathrm{M} \mathrm{Cu}^{+2}$} \\
\hline & Control & $+\mathrm{CH} 34$ & Control & $+\mathrm{CH} 34$ & Control & $+\mathrm{CH} 34$ & Control & $+\mathrm{CH} 34$ \\
\hline B & $21.0 \pm 0.7^{*}$ a & $27.5 \pm 2.2 \mathbf{b}$ & $44.0 \pm 3.4 \mathrm{c}$ & $57.3 \pm 5.3 \mathbf{d}$ & $14.6 \pm 1.9 \mathbf{a}$ & $19.3 \pm 0.9 \mathbf{b}$ & $70.1 \pm 23.4 \mathbf{c}$ & $59.2 \pm 23.9 \mathbf{c}$ \\
\hline Co & $0.2 \pm 0.0 \mathbf{a}$ & $0.3 \pm 0.0 \mathbf{b}$ & $0.3 \pm 0 \mathbf{c}$ & $0.5 \pm 0.0 \mathrm{~d}$ & $0.5 \pm 0.1 \mathbf{a}$ & $0.9 \pm 0.0 \mathbf{b}$ & $0.6 \pm 0.1 \mathbf{a}$ & $1.0 \pm 0.1 \mathbf{b}$ \\
\hline $\mathbf{C u}$ & $4.5 \pm 0.1 \mathbf{a}$ & $4.7 \pm 0.2 \mathbf{b}$ & $186.9 \pm 6.1 \mathbf{c}$ & $289.0 \pm 1.4 \mathbf{d}$ & $5.2 \pm 0.2 \mathbf{a}$ & $6.2 \pm 0.3 \mathbf{b}$ & $308.5 \pm 13.8 \mathbf{c}$ & $426.2 \pm 20 \mathbf{d}$ \\
\hline Fe & $118.0 \pm 5.2 \mathbf{a}$ & $167.9 \pm 8.9 b$ & $445.0 \pm 34.4 \mathbf{c}$ & $484.1 \pm 11.5 \mathrm{~d}$ & $2671.2 \pm 267.9 \mathrm{a}$ & $5091.6 \pm 181.2 \mathbf{b}$ & $11098.0 \pm 336.9 \mathbf{c}$ & $7636.7 \pm 377.7 \mathbf{d}$ \\
\hline Mn & $196.5 \pm 8.9 \mathbf{a}$ & $217.7 \pm 12.1 \mathbf{b}$ & $262.6 \pm 15.4 \mathrm{c}$ & $350.4 \pm 7.2 \mathbf{d}$ & $111.3 \pm 8.8 \mathbf{a}$ & $163.0 \pm 4.4 \mathbf{b}$ & $177.1 \pm 9.7 \mathbf{c}$ & $195.2 \pm 12.2 \mathbf{d}$ \\
\hline Mo & $19.5 \pm 0.5 \mathbf{a}$ & $18.4 \pm 2.2 \mathbf{a}$ & $14.3 \pm 0.4 \mathbf{b}$ & $23.0 \pm 1.2 \mathbf{c}$ & $66.1 \pm 7.2 \mathbf{a}$ & $25.8 \pm 4.7 \mathbf{b}$ & $21.3 \pm 4.1 \mathbf{c}$ & $35.0 \pm 1.6 \mathbf{b}$ \\
\hline $\mathbf{Z n}$ & $191.4 \pm 18.2 \mathrm{a}$ & $191.8 \pm 14.7 \mathbf{a}$ & $295.7 \pm 15.1 \mathbf{b}$ & $359.2 \pm 1.5 \mathbf{c}$ & $940.4 \pm 58.8 \mathbf{a}$ & $1299.2 \pm 56.2 \mathbf{b}$ & $1222.8 \pm 46.7 \mathbf{c}$ & $2091.8 \pm 107.8 \mathbf{d}$ \\
\hline
\end{tabular}

$4^{*}$ All values are expressed as $\mu \mathrm{g}$ metal $\mathrm{g}^{-1}$ of dry weight. $\mathrm{MS}^{1} / 2$ corresponds to half-diluted standard

5Murashige-Skoog plant growth medium. $\mathrm{MS}^{1} / 2+50 \mu \mathrm{M} \mathrm{Cu}^{+2}$ indicates same medium supplemented 6with $50 \mu \mathrm{M} \mathrm{CuSO}_{4} \times 5 \mathrm{H}_{2} \mathrm{O}$. Each condition had three technical replicates consisting of at least $8 \mathrm{mg}$ of 7rosette or root material. Different letters represent significant differences between rosette or root levels 8of each metal (two-way ANOVA, $\mathrm{p}<0.05$; Tukey test, $\mathrm{p}<0.05$ ). 


\section{Table 3(on next page)}

Table 3

Table 3. Percentage of metal accumulation in rosettes and roots of Arabidopsis thaliana 21 days after sowing, inoculated or not with Cupriavidus metallidurans $\mathrm{CH} 34$, in the presence or absence of copper. 
1 Table 3. Percentage of metal accumulation in rosettes and roots of Arabidopsis thaliana 21

2 days after sowing, inoculated or not with Cupriavidus metallidurans CH34, in the presence

3 or absence of copper.

\begin{tabular}{|c|c|c|c|c|c|c|}
\hline & \multicolumn{2}{|c|}{ Rosettes (CH34/control) } & \multicolumn{2}{|c|}{ Roots (CH34/control) } & \multirow[t]{2}{*}{ Rosettes $(\mathrm{Cu} /$ control $)$} & \multirow[t]{2}{*}{ Roots $(\mathrm{Cu} /$ control $)$} \\
\hline Element & $\mathrm{MS}^{1 / 2}$ & $\begin{array}{c}\mathrm{MS}^{1 / 2}+50 \\
\mu \mathrm{M} \mathrm{Cu}^{2+}\end{array}$ & $\mathrm{MS}^{1 / 2}$ & $\begin{array}{c}\mathrm{MS}^{1 / 2}+50 \\
\mu \mathrm{M} \mathrm{Cu}^{2+}\end{array}$ & & \\
\hline $\mathbf{B}$ & $+29 \% * *$ & $+30 \%$ & $+32 \%$ & - & $+109 \%$ & $+380 \%$ \\
\hline Co & $+68 \%$ & $+40 \%$ & $+67 \%$ & $+73 \%$ & $+50 \%$ & $+20 \%$ \\
\hline $\mathbf{C u}$ & $+11 \%$ & $+55 \%$ & $+18 \%$ & $+38 \%$ & +315 & $+493 \%$ \\
\hline $\mathbf{F e}$ & $+42 \%$ & $+9 \%$ & $+91 \%$ & $-31 \%$ & $+277 \%$ & $+315 \%$ \\
\hline Mn & $+11 \%$ & $+33 \%$ & $+46 \%$ & $+10 \%$ & $+33 \%$ & $+59 \%$ \\
\hline Mo & - & $+60 \%$ & $-61 \%$ & $+64 \%$ & $-27 \%$ & $-69 \%$ \\
\hline $\mathbf{Z n}$ & - & $+21 \%$ & $+38 \%$ & $+71 \%$ & $+54 \%$ & $+30 \%$ \\
\hline
\end{tabular}

$4 * *$ All values were calculated as percentages of the metal level ( $\mu \mathrm{g}$ of metal $\mathrm{g}^{-1}$ of dry weight) in

5 inoculated versus non-inoculated plants (CH34/control), and plants in the presence or absence of

6 copper $(\mathrm{Cu} /$ control). -: Not significant changes. 


\section{Table 4 (on next page)}

\section{Table 4}

Table 4. Translocation factors (TF) for each metal in Arabidopsis thaliana inoculated or not with Cupriavidus metallidurans $\mathrm{CH} 34$, in the presence or absence of copper. 
1 Table 4. Translocation factors (TF) for each metal in Arabidopsis thaliana inoculated or not 2 with Cupriavidus metallidurans $\mathrm{CH34}$, in the presence or absence of copper.

\begin{tabular}{|c|c|c|c|c|}
\hline & \multicolumn{2}{|c|}{ MS $1 / 2$} & \multicolumn{2}{|c|}{$\mathrm{MS}^{1} / 2+50 \mu \mathrm{M} \mathrm{Cu} \mathbf{u}^{+2}$} \\
\hline & $\mathbf{T F}_{\text {Control }}$ & $\mathbf{T F}_{\mathrm{CH} 34}$ & $\mathbf{T F}_{\text {Control }}$ & $\mathbf{T F}_{\mathrm{CH} 34}$ \\
\hline B & $1.6^{\mathrm{a}}$ & $1.3^{\mathrm{a}}$ & $0.7^{\mathbf{b}}$ & $1.1^{\mathrm{b}}$ \\
\hline Co & $0.4^{\mathrm{a}}$ & $0.4^{\mathrm{a}}$ & $0.6^{\mathbf{b}}$ & $0.5^{\mathrm{a}}$ \\
\hline Mo & $0.3^{\mathrm{a}}$ & $0.8^{\mathbf{b}}$ & $0.7^{\mathbf{b}}$ & $0.7^{\mathbf{b}}$ \\
\hline $\mathbf{C u}$ & $0.9^{\mathrm{a}}$ & $0.8^{\mathbf{b}}$ & $0.6^{\mathrm{c}}$ & $0.7^{\mathrm{d}}$ \\
\hline Mn & $1.9^{\mathrm{a}}$ & $1.3^{\mathrm{b}}$ & $1.5^{\mathrm{c}}$ & $1.8^{\mathrm{d}}$ \\
\hline $\mathbf{F e}$ & $0.04^{\mathrm{a}}$ & $0.03^{b}$ & $0.04^{\mathrm{a}}$ & $0.06^{\mathrm{c}}$ \\
\hline $\mathbf{Z n}$ & $0.2^{\mathrm{a}}$ & $0.1^{\mathrm{b}}$ & $0.2^{\mathrm{c}}$ & $0.1^{\mathrm{d}}$ \\
\hline
\end{tabular}

$3 \mathrm{TF}$ was calculated as $=\left(\right.$ Metal concentration Rosette $/$ Metal concentration $\left._{\text {Root }}\right) . \mathrm{MS}^{1} / 2$ corresponds to

4 half-diluted standard Murashige-Skoog plant growth medium. $\mathrm{MS}^{1 / 2}+50 \mu \mathrm{M} \mathrm{Cu}^{+2}$ indicates same

5 medium supplemented with $50 \mu \mathrm{M} \mathrm{CuSO}_{4} \times 5 \mathrm{H}_{2} \mathrm{O}$. Each condition had three technical replicates

6 consisting of at least $8 \mathrm{mg}$ of rosette or root material. Different letters represent significant

7 differences between treatments (two-way ANOVA, $\mathrm{p}<0.05$; Tukey test, $\mathrm{p}<0.05$ ). 


\section{Table 5 (on next page)}

Table 5

Table 5. Colony forming units of Cupriavidus metallidurans $\mathrm{CH} 34$ by milligram of fresh weight (CFU mg ${ }^{-1} \mathrm{FW}$ ) of plant, agar surrounding plant (rhizosphere), and non-planted $\mathrm{MS}^{1} / 2$ agar medium (non-rhizosphere). 
1 Table 5. Colony forming units of Cupriavidus metallidurans CH34 by milligram of fresh

2 weight (CFU mg-1 FW) of plant, agar surrounding plant (rhizosphere), and non-planted

$3 \mathrm{MS}^{1} / 2$ agar medium (non-rhizosphere).

\begin{tabular}{|c|c|c|c|}
\hline Treatment & 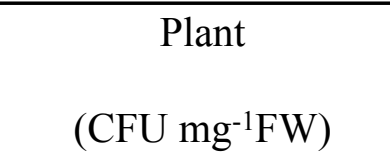 & $\begin{array}{l}\text { Rhizosphere } \\
\text { (CFU mg-1FW) }\end{array}$ & $\begin{array}{l}\text { Non-rhizosphere } \\
\left(\mathrm{CFU} \mathrm{mg} \mathrm{m}^{-1} \mathrm{FW}\right)\end{array}$ \\
\hline $\operatorname{MS}(1 / 2)$ & $5.8 \times 10^{8} \pm 4.7 \times 10^{8} \mathbf{a}$ & $1.0 \times 10^{7} \pm 8.5 \times 10^{6} \mathbf{a}$ & $1.7 \times 10^{4} \pm 1.1 \times 10^{4} \mathrm{a}$ \\
\hline $\mathrm{MS}(1 / 2)+50 \mu \mathrm{M} \mathrm{Cu}^{2+}$ & $1.8 \times 10^{9} \pm 7.5 \times 10^{7} \mathrm{a}$ & $1.4 \times 10^{6} \pm 1.2 \times 10^{6} \mathbf{b}$ & $3.6 \times 10^{4} \pm 1.3 \times 10^{4} \mathbf{b}$ \\
\hline
\end{tabular}

5 C. metallidurans $\mathrm{CH} 34 \mathrm{CFU} \mathrm{mg}^{-1} \mathrm{FW}$ were counted in 21 days after sowing plants, rhizosphere

6 agar and non-rhizosphere $\mathrm{MS}^{1}{ }_{2}$ agar, in 0 and $50 \mu \mathrm{M} \mathrm{CuSO}_{4} \times 5 \mathrm{H}_{2} \mathrm{O}$ treatments. The average

7 values of 15-20 replicates and respective standard deviations are shown. FW corresponds to that

8 of plant or agar material. Different letters in same column indicate statistically significant

9 differences according to a t-test, $\mathrm{p}<0.05$.

10 


\section{Figure 1}

V2 Fig. 1

Fig. 1. Effect of Cupriavidus metallidurans $\mathrm{CH} 34$ on growth parameters of

Arabidopsis thaliana. Rosette area, primary root growth, secondary roots and fresh and dry weights of $A$. thaliana Col-0 grown in in vitro gnotobiotic cultures using half strength Murashige-Skoog (MS) agar medium, inoculated with $1 \times 10^{4}$ colony forming units per milliliter of $\mathrm{C}$. metallidurans $\mathrm{CH} 34$. Forty plants per condition were inoculated or not at day 1 and the half strength MS medium was supplemented with 0 to $70 \mu \mathrm{M} \mathrm{CuSO}{ }_{4} \times 5 \mathrm{H}_{2} \mathrm{O}$. (A) Representative control and strain $\mathrm{CH} 34$ inoculated plants grown in the presence of different $\mathrm{Cu}$ concentrations. (B) Plant growth parameters registered after 21 days of sowing. Bars show mean percentage values, and error bars indicate standard deviations from experiments with 30 plants analyzed for each bacterial condition. Different letters indicate statistically significant differences among treatments at each copper concentration for each measured parameter (Two way ANOVA Tukey's HSD tests; $p<0.05$ ). 
A

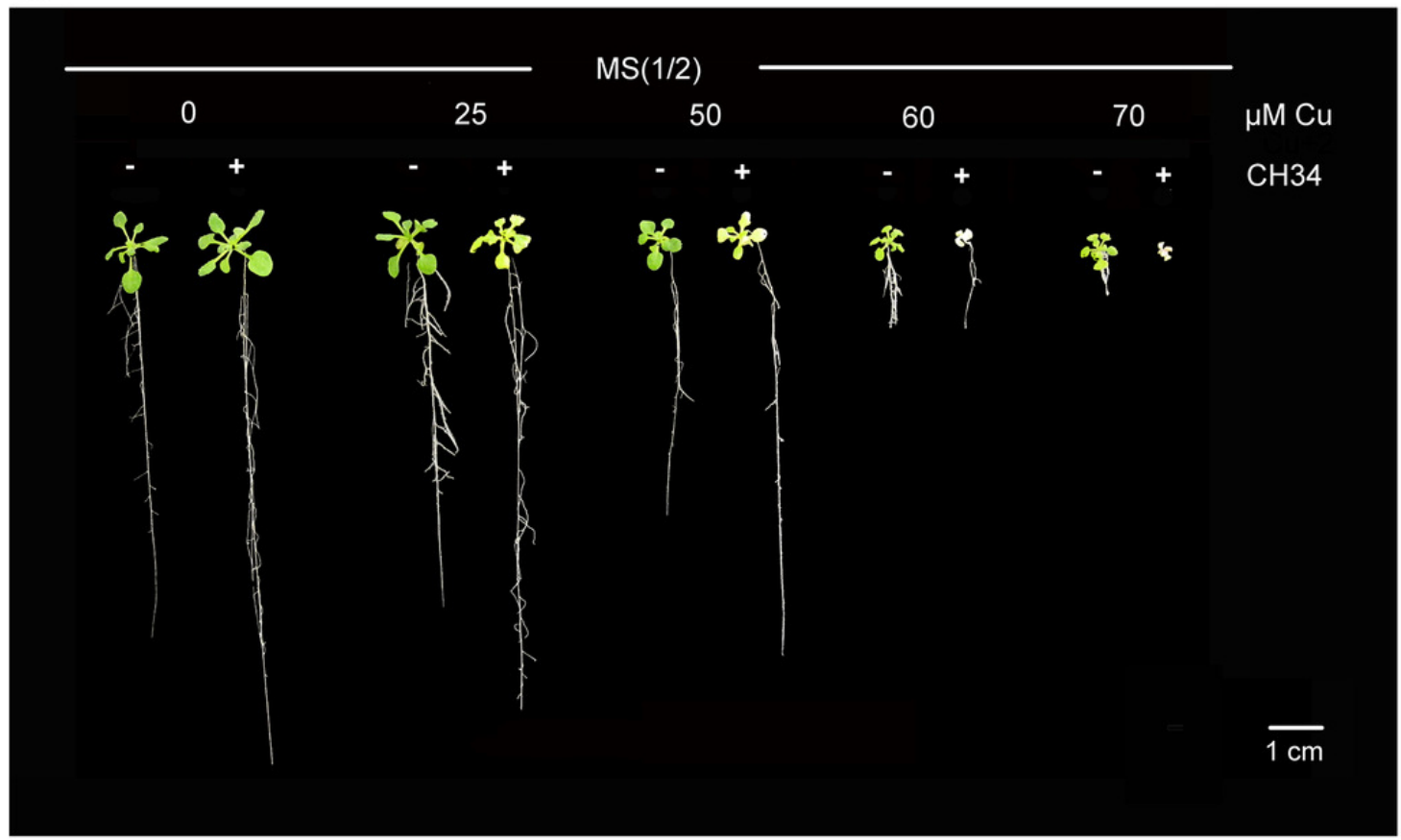

B

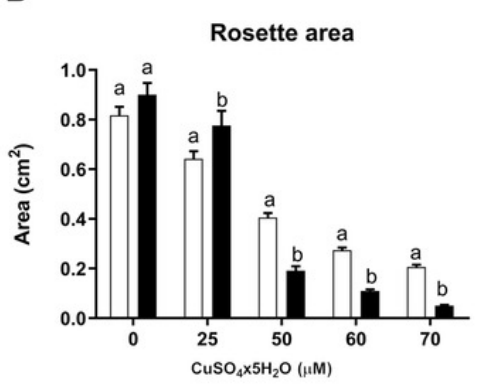

D

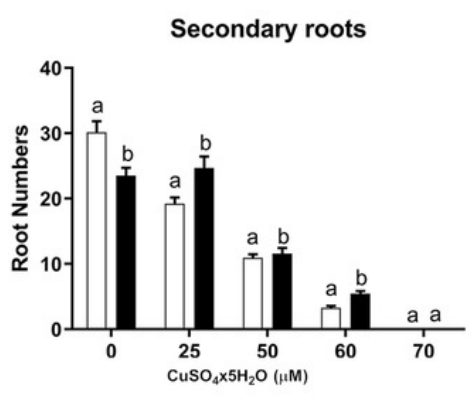

C

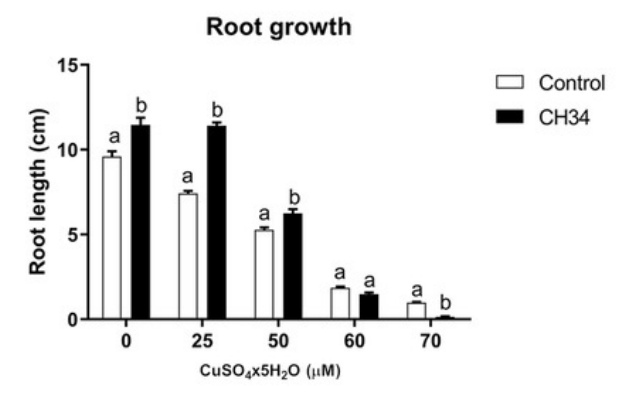

E

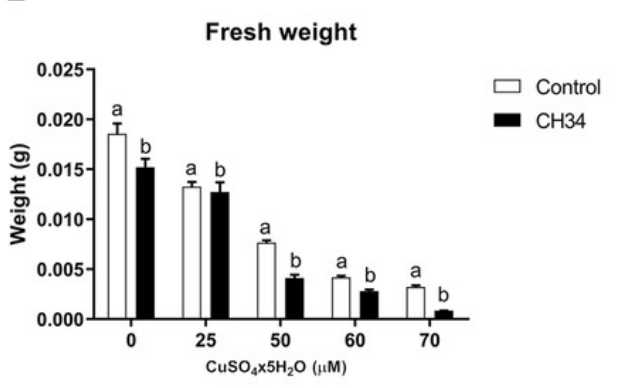

$\mathbf{F}$

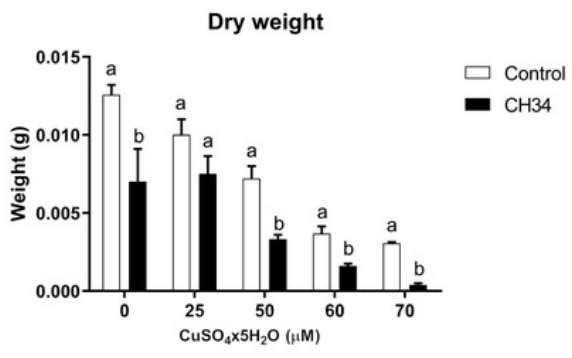




\section{Figure 2}

BG PeerJ Fig 2

Fig. 2. Relative expression levels of Cu resistance genes from Cupriavidus metallidurans $\mathrm{CH} 34$, in the presence or in the absence of Arabidopsis thaliana (At) or copper. Quantitative Real Time Polymerase Chain Reactions determinations of relative expression levels of (A) copK, (B) copF, (C) copC, and (D) copC 2 genes. Expression levels were normalized respect to the housekeeping gene 16S rRNA. Data correspond to means \pm standard deviations of at least three biological replicates. Different letters indicate significant differences between same time conditions (Two way ANOVA Tukey's HSD tests; $p<0.05$ ). 
A

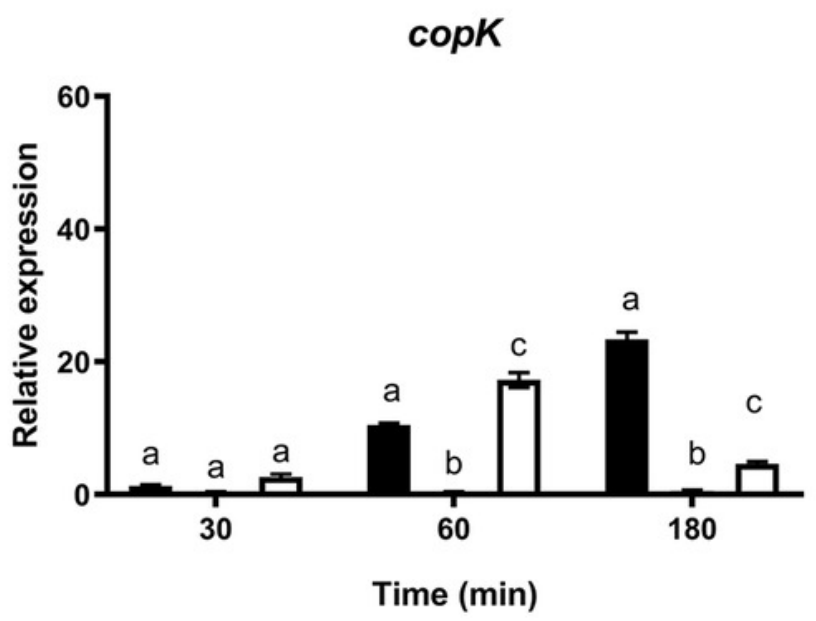

C

copC

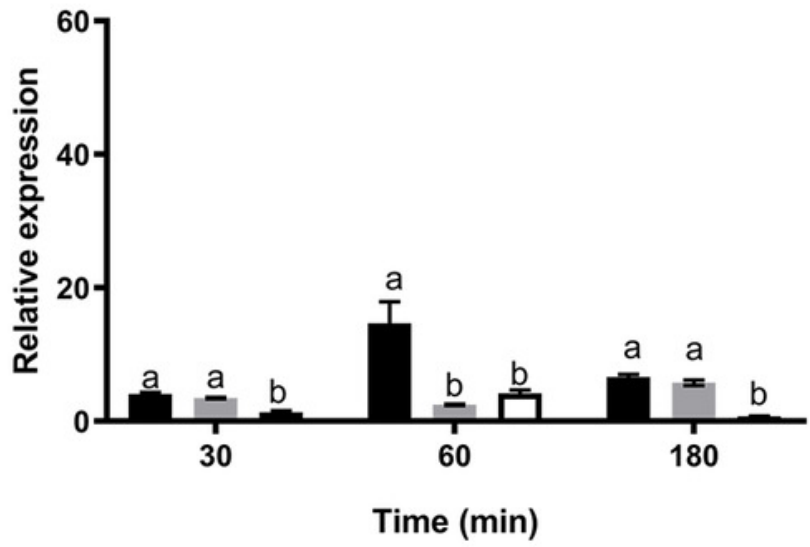

- Plant $+25 \mu \mathrm{M} \mathrm{Cu}^{2+}$
B

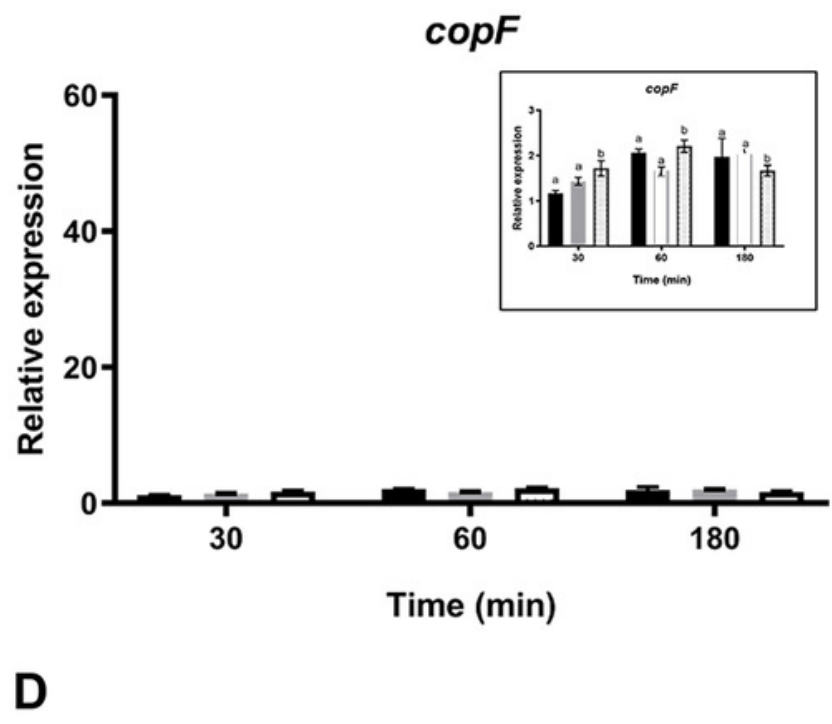

$\operatorname{copC} 2$

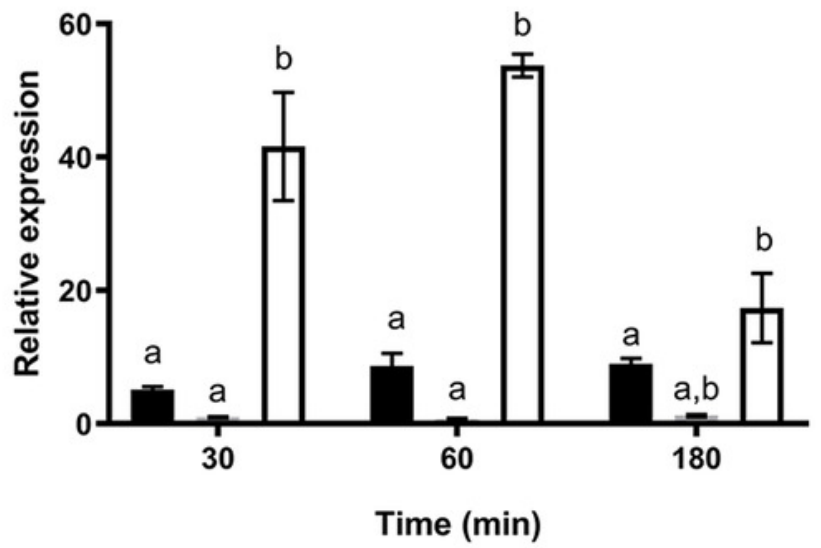

Plant (At)

$\square 25 \mu \mathrm{M} \mathrm{Cu}^{2+}$ 


\section{Figure 3}

BG PeerJ Fig 3

Fig. 3. Relative expression levels of staphyloferrin B siderophore production genes from Cupriavidus metalliduransCH34, in the presence or in the absence of Arabidopsis thaliana (At) or copper. Quantitative Real Time Polymerase Chain Reactions determinations of relative expression levels of (A) fur (aleO), (B) iucA, (C) aleB, and (D) piuA genes. Expression levels were normalized respect to the housekeeping gene 16S rRNA. Data correspond to means \pm standard deviations of at least three biological replicates. Different letters indicate significant differences between same time conditions (Two way ANOVA Tukey's HSD tests; $p<0.05)$. 
A

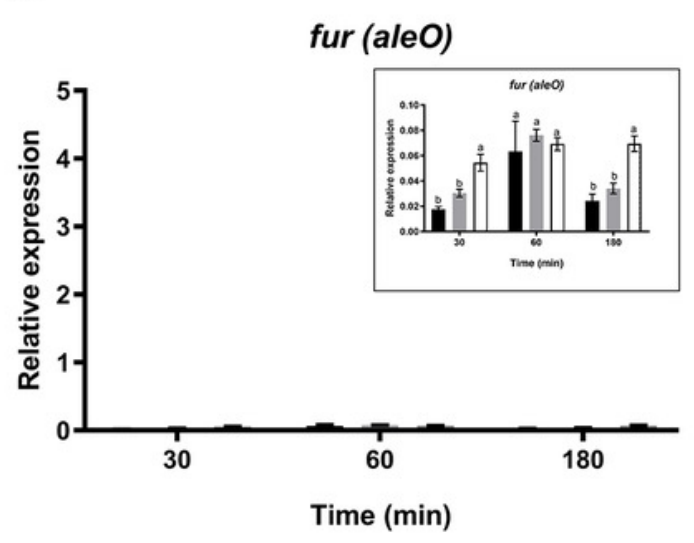

C

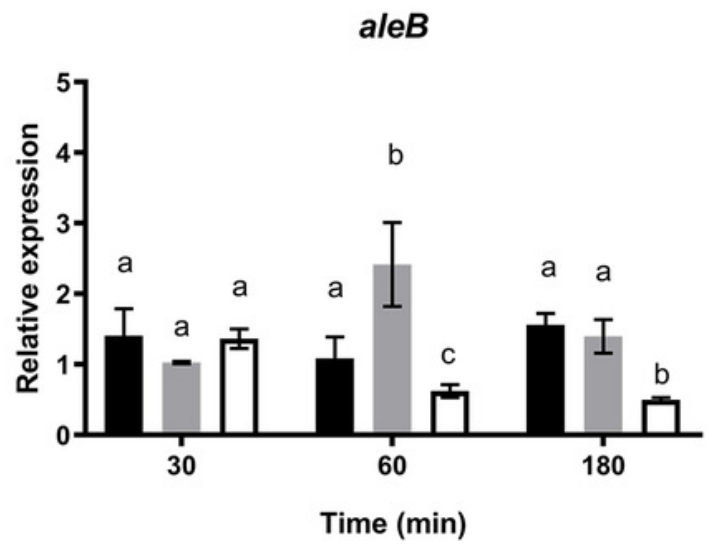

- Plant $+25 \mu \mathrm{M} \mathrm{Cu}^{2+}$
B

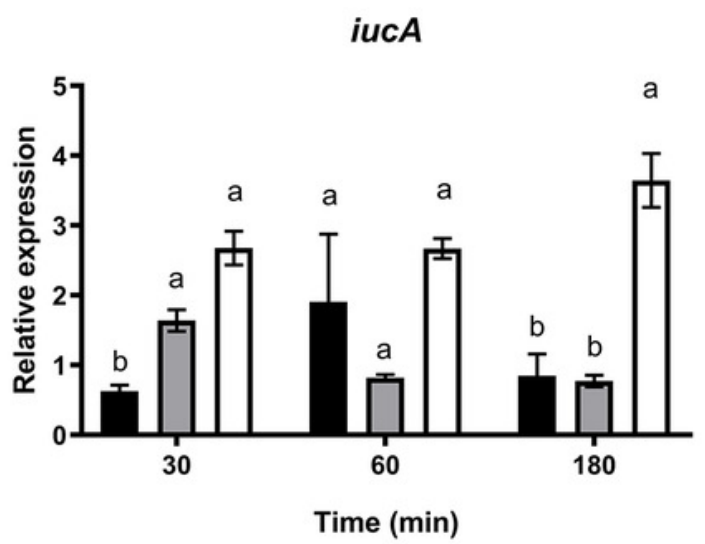

D

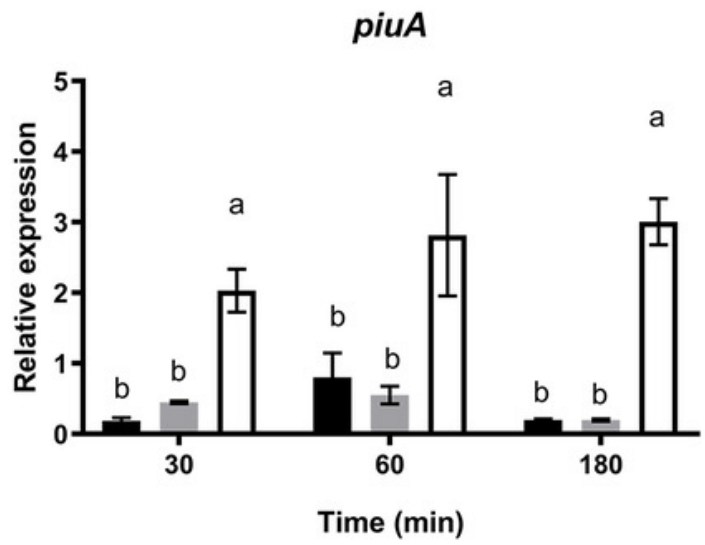

Plant (At)
口 $25 \mu \mathrm{M} \mathrm{Cu}^{2+}$ 